\title{
On Material Transport by Shelfbreak Eddies
}

\author{
OLIVIER MARCHAL \\ Woods Hole Oceanographic Institution, Woods Hole, Massachusetts
}

(Manuscript received 11 August 2018, in final form 12 December 2018)

\begin{abstract}
The Lagrangian motion in the eddy field produced from an unstable retrograde jet along the shelf break is studied from idealized numerical experiments with a primitive equation model. The jet is initially in thermal wind balance with a cross-isobath density gradient and is not subjected to any atmospheric forcing. Over the course of the model integration, the jet becomes unstable and produces a quasi-stationary eddy field over a 2-month period. During this period, the cross-slope flow at the shelf break is characterized by along-slope correlation scales of $O(10) \mathrm{km}$ and temporal correlation scales of a few days. The relative dispersion of parcels across isobaths is found to increase with time as $t^{b}$, where $1<b<2$. This mixed diffusive-ballistic regime appears to reflect the combined effects of (i) the short length scales of velocity correlation at the shelf break and (ii) the seaward excursion of monopolar and dipolar vortices. Cross-slope dispersion is greater offshore of the front than inshore of the front, as offshore parcels are both subducted onshore below density surfaces and translated offshore with eddies. Nonetheless, the exchange of parcels across the jet remains very limited on the monthly time scale. Particles originating from the bottom experience upward displacements of a few tens of meters and seaward displacements of $O(100) \mathrm{km}$, suggesting that the eddy activity engendered by an unstable along-slope jet provides another mechanism for bottom boundary layer detachment near the shelf edge.
\end{abstract}

\section{Introduction}

Dynamical processes at the shelf break determine the exchange of material and energy between the continental shelf and the continental slope (for reviews, see Huthnance 1995; Brink 2016b). These processes are of paramount importance to a variety of oceanographic phenomena, such as the maintenance of the freshwater balance of the shelf region, the fate of pollutants discharged into the coastal zone, and the offshore export of dissolved substances and solid particles from the shelf. The shelf break is often the site of significant gradients of temperature and salinity in the cross-isobath direction, reflecting the different properties of shelf and slope waters. If the resulting density gradient is large enough, an along-isobath current in approximate thermal wind balance can be observed at the shelf edge. The presence of such a current suggests that dynamical conditions at the shelf edge are not particularly favorable to material transport between the shelf and slope regions, that is, motions that are

Corresponding author: Olivier Marchal, omarchal@whoi.edu conducive to material transport across the shelf break would be primarily ageostrophic.

A well-studied example of a shelfbreak front occurs in the Middle Atlantic Bight (MAB), between Cape Hatteras to the southwest and Georges Bank to the northeast. The front separates the cold and low-salinity waters of the continental shelf from the warm and highsalinity waters of the continental slope (e.g., Linder and Gawarkiewicz 1998). This partially compensated front is retrograde in the sense that the density surfaces in the frontal region tilt upward in the offshore direction, that is, in the opposite direction to the bottom slope. Linder and Gawarkiewicz (1998) depicted the mean state of the front from hydrographic data collected from off the coast of New Jersey, south of the Nantucket Shoals, and along the southern flank of Georges Bank. The nearsurface density gradients were found to be strongest during the winter and weakest during the summer when the seasonal thermocline isolates much of the front from the surface. Despite the underestimation of frontal density gradients due to data averaging in time and space, the inferred geostrophic velocity field south of Nantucket was characterized by a strong baroclinic jet $\left(0.2-0.3 \mathrm{~m} \mathrm{~s}^{-1}\right)$. The core of the jet had a width estimated 
to $15-20 \mathrm{~km}$ and was found to be located near the $150-\mathrm{m}$ isobath. In a subsequent study, Fratantoni et al. (2001) analyzed a collection of highly resolved velocity sections obtained from acoustic Doppler current profiler (ADCP) deployed across the shelfbreak jet south of Nantucket over a period of 2 years. The velocity sections were averaged with respect to a translating coordinate system aligned with the jet core in order to reduce variability associated with the lateral meandering of the jet. The mean jet so constructed was found to extend to the bottom, with near-bottom velocity $>0.10 \mathrm{~m} \mathrm{~s}^{-1}$, and to tilt onshore with depth. Flagg et al. (2006) analyzed 10 years of upper-ocean ADCP data collected between New York and Bermuda by the container ship Oleander. The data corrected for the effects of warm ring revealed an Eulerian mean velocity structure characterized by an along-isobath shelfbreak jet with maximum speeds of $O(0.15) \mathrm{m} \mathrm{s}^{-1}$. The shelfbreak jet transport was estimated to average $0.4 \mathrm{~Sv}(1 \mathrm{~Sv}=$ $\left.10^{6} \mathrm{~m}^{3} \mathrm{~s}^{-1}\right)$, with maximum values in the fall and winter. In stream coordinates, the jet had maximum speeds of $0.35 \mathrm{~m} \mathrm{~s}^{-1}$, a width of $\sim 30 \mathrm{~km}$, and a vertical scale of $\sim 50 \mathrm{~m}$. The maximum Rossby number within the jet was estimated to about 0.2. More recently, Zhang et al. (2011) reported, from a temperature and salinity climatology, that a surface jet is present south of New England in all seasons but varies in strength and crossshelf position: it is strongest $\left(\sim 0.12 \mathrm{~m} \mathrm{~s}^{-1}\right)$ and farthest offshore in winter, and it is weakest $\left(\sim 0.07 \mathrm{~m} \mathrm{~s}^{-1}\right)$ and farthest onshore in summer.

The shelfbreak front of the MAB exhibits high temporal and spatial variability. Garvine et al. (1988) combined buoy tracking, hydrographic data, and satellite thermal imagery to study variability at the shelfbreak front. A satellite thermal image for 26 May 1982 showed that small-scale eddies were present all along the front from the New York Bight apex eastward past Cape Cod and onto the margin of Georges Bank. Both cyclonic and anticyclonic eddies appeared, characterized by a typical diameter of about $40 \mathrm{~km}$. Eddy-like features were always present at the front throughout the 15-day period of their investigation (June 1984). Gawarkiewicz et al. (2004) conducted repeated surveys of the shelfbreak front south of New England using a towed undulating vehicle (SeaSoar) deployed from 26 July to 1 August 1996. The frontal variability was dominated by the westward propagation of a meander with a wavelength of $40 \mathrm{~km}$, a propagation speed of $0.11 \mathrm{~m} \mathrm{~s}^{-1}$, and a horizontal amplitude of $15 \mathrm{~km}(30 \mathrm{~km}$ crest to through). Alongfront geostrophic speeds were as large as $0.45 \mathrm{~m} \mathrm{~s}^{-1}$ and showed significant alongfront variations. The relative vorticity within the frontal jet was also large, reaching up to 0.6 of the local planetary vorticity. The authors concluded that, at least during some time periods, exchange at the shelf break is nonlinear (large Rossby number) and dominated by features with a horizontal scale of $O(10) \mathrm{km}$. In their analysis of observations made along the Oleander line, Flagg et al. (2006) reported significant interannual fluctuations in the upper-ocean temperature, salinity, and currents near the shelf edge. Todd et al. (2013) deployed gliders to document thermohaline variability over the shelf break and continental rise. They inferred horizontal scales of variability increasing from 8 to $13 \mathrm{~km}$ near the shelf break to about $30 \mathrm{~km}$ over the rise. Offshore of the shelf break, along-slope structures presented horizontal scales of $40-50 \mathrm{~km}$, consistent with the wavelength of shelfbreak frontal meanders. From maps of sea surface temperature measured by satellite, Zhang and Gawarkiewicz (2015) estimated frontal wavelengths of about 25,40 , and $60 \mathrm{~km}$, depending on location and time.

Evidence for material exchange across the shelf break of the MAB is available from a variety of observations. Paired measurements of salinity and oxygen isotopic composition showed that waters from the northern half of the MAB are a mixture of waters from the Scotian Shelf and the continental slope; waters from the southern half of the MAB are further influenced by river runoff (e.g., Chapman et al. 1986). Near-surface drifters released in the vicinity of Georges Bank have been shown to be detrained both onshore and offshore of the shelfbreak front, with offshore detrainment being predominant (Lozier and Gawarkiewicz 2001). The sites for offshore detrainment were distributed rather uniformly along the MAB, suggesting that local bathymetric features were not the primary conduits for crossfrontal exchange. Churchill and Gawarkiewicz (2009) presented temperature, salinity, and velocity data from a series of shipboard transects over the slope of the southern MAB. Attention was paid to a cyclonic eddy of roughly $60-\mathrm{km}$ diameter and 300-m depth, which translated southward at a speed of $0.1 \mathrm{~m} \mathrm{~s}^{-1}$. The eddy was found to be a mixture of waters originating from the shelf, the shelf break, and the slope, as well as from the Gulf Stream. In the upper $100 \mathrm{~m}$, shelfbreak frontal water was estimated to contribute about $75 \%$ of the volume of the eddy. In his analysis of the salt budget of the MAB, Lentz (2010) concluded that the southward increase in the depth-averaged salinity of 1 psu $(1000 \mathrm{~km})^{-1}$ at midshelf must be balanced by a substantial onshore flux of salt.

Several mechanisms have been proposed to explain the material exchange across the shelf break in the MAB (for short reviews, see Garvine et al. 1988; Lozier and Gawarkiewicz 2001). These include, for example, 
the interaction of the frontal jet with warm core rings spawned from the Gulf Stream, surface mixed layer transport due to wind stress from synoptic weather systems, and the local instability of the current (Lozier and Gawarkiewicz 2001). The latter mechanism has received particular attention from a theoretical standpoint (e.g., Flagg and Beardsley 1978; Gawarkiewicz 1991; Lozier et al. 2002; Lozier and Reed 2005). For example, Lozier et al. (2002) considered a continuously stratified model based on the linearized primitive equations to study the frontal variability observed at the shelf break. The shelfbreak frontal jet in their model was shown to be unstable to three-dimensional (3D) perturbations over the wide parameter range derived from the observed velocity and density distributions. Perturbation growth rates of $O(1)$ day for wavelengths of $10-50 \mathrm{~km}$ compared favorably with observations (Garvine et al. 1988; see also Zhang and Gawarkiewicz 2015), suggesting that local baroclinic and/or barotropic instabilities are a likely source for the strong variability of the shelfbreak front.

Observational evidence for a role of baroclinic instability in the variability of the MAB shelfbreak front has been reported in the literature. Fratantoni and Pickart (2003) presented velocity records from two bottom-mounted ADCPs deployed at the shelf edge south of New England in order to characterize the mesoscale variability in the region. While the jet was found to be equatorward on average, the 18-month record was dominated by strong fluctuations at a period of near 13 days. The origin of the fluctuations was explored using local wind records, concurrent velocity data from three tall current meter moorings on the continental slope, and information about the position of the Gulf Stream front. The authors concluded that, among the mechanisms considered, the fluctuations are most likely caused by the baroclinic instability of the shelfbreak jet, although they cautioned that (i) their records differ from historical observations and (ii) existing stability models tend to oversimplify the main features of the jet. In their study of a cyclonic eddy over the slope of the southern MAB, Churchill and Gawarkiewicz (2009) concluded that the eddy developed rapidly ( $<3$ days), consistent with eddy generation through the baroclinic instability of the shelfbreak frontal jet.

Another mechanism of material exchange across the shelf break of the MAB is the detachment and seaward export of the bottom boundary layer (BBL) near the shelf edge. Tracer release experiments with dye injected into the BBL at the foot of the shelfbreak front suggested that the flow was convergent and upward within the front (Houghton 1997; Houghton and Visbeck 1998). Likewise, convergence in the BBL and subsequent upwelling into the interior were suggested by optical data, revealing the presence of a particle-rich region at middepth, emanating from the foot of the front and extending $80 \mathrm{~m}$ above the bottom (Barth et al. 1998). Pickart (2000) reported from a cross-shelf section of CTD and ADCP data taken south of New England that the BBL vanishes at the shoreward edge of the front and detaches into the interior along a (nearly) isopycnal layer. Using a collection of transects across the front, Linder et al. (2004) later concluded that the isopycnal at which detachment occurs is fairly constant throughout the year. On the other hand, the vertical extent of the detached layer was estimated to vary with season, from $60-80 \mathrm{~m}$ in winter and spring to $20-40 \mathrm{~m}$ in summer, which was interpreted as reflecting a control by the strength and depth of the seasonal pycnocline. Model studies showed that the detachment of a BBL from a sloping bottom could be due to the establishment of an adverse pressure gradient along the bottom (Gawarkiewicz and Chapman 1992) or the trapping of a surface-to-bottom density front to an isobath (Chapman and Lentz 1994).

In this paper, a regional model based on the primitive equations is used to investigate the transport of material associated with the eddying flow produced from an unstable retrograde jet at the shelf break. Our goal is to study the Lagrangian motion in a fully developed eddy field, thereby complementing previous studies based on linear stability analyses (e.g., Lozier et al. 2002; Lozier and Reed 2005) and numerical models of the Eulerian circulation in the MAB (e.g., Chen and $\mathrm{He}$ 2010; Zhang et al. 2011; Zhang and Gawarkiewicz 2015; Benthuysen et al. 2015). From their synthesis of observations, Garvine et al. (1988) concluded that winds were light and seemed not important to shelfbreak eddies. Here an idealized model domain is considered with no atmospheric forcing in order to isolate the cross-slope transport of material induced by an unstable shelfbreak jet. We study the ability of the resulting eddy field to move fluid particles between the shelf and the deep basin at different depths, including near the bottom.

The remainder of this paper is organized as follows. In section 2, the domain and governing equations of the circulation model are briefly described together with its initial and boundary conditions. In section 3, the instability of the shelfbreak front, the evolution of kinetic and potential energies of the eddying flow, and the horizontal and temporal scales of the associated cross-slope exchange are first illustrated. The crossslope dispersion of fluid particles in the eddy field, the chief topic of this paper, is then characterized and quantified. In section 4, our numerical results are 


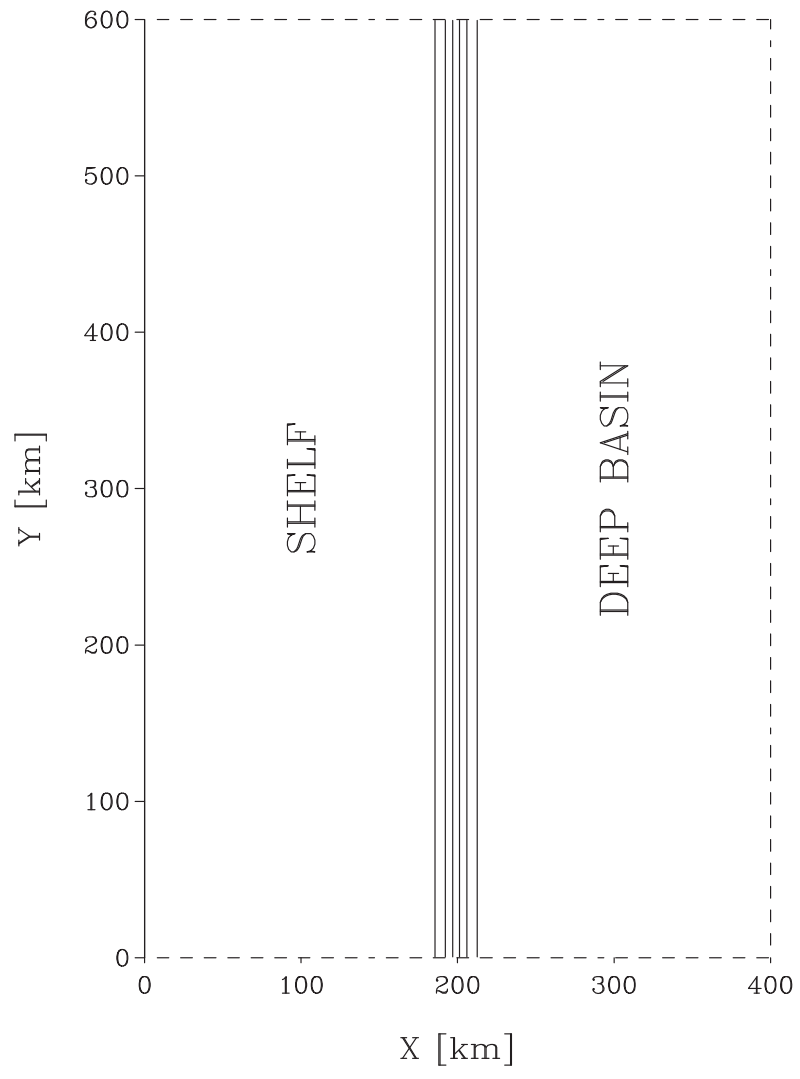

FIG. 1. Model domain, representing a continental shelf, a continental slope, and a deep basin. Isobaths from 80 to $180 \mathrm{~m}$ are shown with solid lines (contour interval $=20 \mathrm{~m}$ ). The boundary at $x=0$ is closed, and the other three boundaries are open.

interpreted in terms of frontal processes. Conclusions follow in section 5 .

\section{Ocean model}

\section{a. Domain}

The model domain is an idealized oceanic margin, comprising a continental shelf, a continental slope, and a deep basin (Fig. 1). The cross-margin coordinate $x$ varies from 0 at the coast (closed boundary) to $L_{x}=400 \mathrm{~km}$ offshore (open boundary). The alongmargin coordinate $y$ varies from 0 to $L_{y}=600 \mathrm{~km}$, where the two boundaries at $y=\left(0, L_{y}\right)$ are open. Although the domain is subjected to uniform rotation and the coordinate $y$ has no geographic meaning, the boundaries at $y=0$ and $y=L_{y}$ are referred to below as the "southern" boundary and "northern" boundary, respectively. The vertical coordinate $z$ increases from $z=-h(x)$ at the bottom to $z=\eta(x, y, t)$ at the free surface.

The model bathymetry is given by

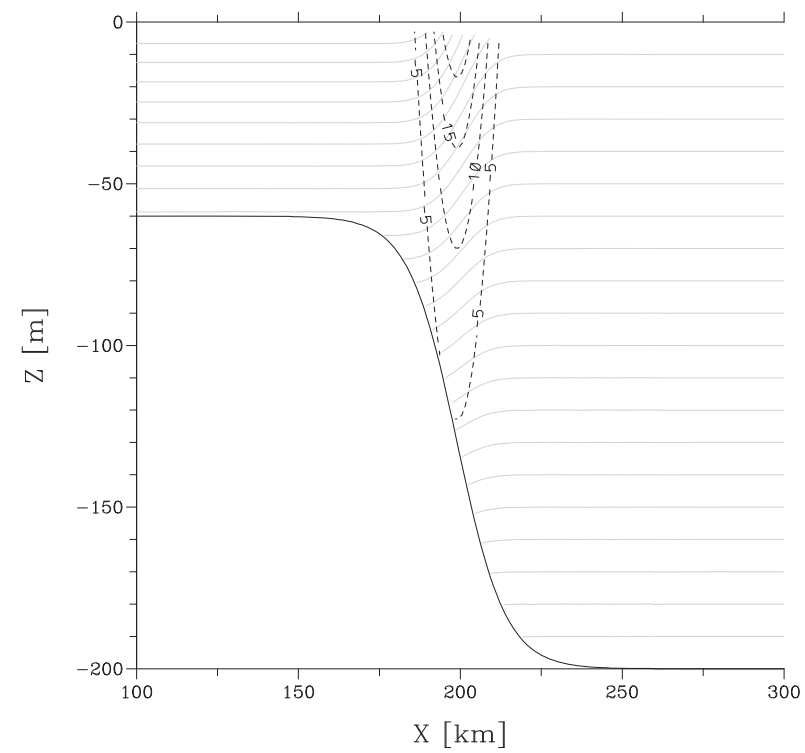

FIG. 2. Initial conditions of the model, characterized by an alongslope jet in thermal wind balance at the shelf break. The isotachs for the along-shelf velocity are shown with black dashed lines (contour interval $=5 \mathrm{~cm} \mathrm{~s}^{-1}$ ) and the isotherms are shown with unlabeled gray lines (contour interval $=0.5^{\circ} \mathrm{C}$ ). The jet flows out of the paper. The topography is displayed with the thick black line.

$$
h(x)=h_{s}+\frac{h_{d}-h_{s}}{2}\left(1+\tanh \frac{x-x_{m}}{x_{s}}\right),
$$

where $h_{s}=60 \mathrm{~m}$ determines the shelf depth, $h_{d}=$ $200 \mathrm{~m}$ is the depth of the basin offshore, $x_{m}=L_{x} / 2=$ $200 \mathrm{~km}$ is the location of maximum bottom slope, and $x_{s}=15 \mathrm{~km}$ is the cross-margin extent of the slope (Fig. 2). For convenience, the location of maximum slope $(x=200 \mathrm{~km})$ is referred to as the shelf break in this study. The profile in (1) approximates bathymetric measurements in the Nantucket Shoals region and has been used in idealized models of the shelfbreak jet in the MAB (Lozier et al. 2002; Lozier and Reed 2005). Although water depths along the continental slope reach much greater values in this region, the choice $h_{d}=200 \mathrm{~m}$ is motivated by a focus on upper-ocean dynamics and a desire to reduce computational cost.

\section{b. Equations of motion}

The ocean model used in this study is the Princeton Ocean Model (POM; the computer code applied here is pom2k.f). POM solves the free-surface primitive equations under the hydrostatic and Boussinesq approximations and in terrain-following (sigma) coordinates (Blumberg and Mellor 1987; Mellor 2002). The basic equations of motion of the model are

$$
\nabla \cdot \mathbf{u}=0
$$




$$
\begin{aligned}
\frac{\partial u}{\partial t}+(\mathbf{u} \cdot \nabla) u-f v & =-\frac{1}{\rho_{o}} \frac{\partial p}{\partial x}+\frac{\partial}{\partial z}\left(\kappa_{m} \frac{\partial u}{\partial z}\right)+F_{u} \\
\frac{\partial v}{\partial t}+(\mathbf{u} \cdot \nabla) v+f u & =-\frac{1}{\rho_{o}} \frac{\partial p}{\partial y}+\frac{\partial}{\partial z}\left(\kappa_{m} \frac{\partial v}{\partial z}\right)+F_{v} \\
0 & =-\frac{1}{\rho} \frac{\partial p}{\partial z}-g, \quad \text { and } \\
\frac{\partial T}{\partial t}+(\mathbf{u} \cdot \nabla) T & =\frac{\partial}{\partial z}\left(\kappa_{T} \frac{\partial T}{\partial z}\right)+F_{T} .
\end{aligned}
$$

Here the dynamical variables are the velocity $\mathbf{u}=$ $(u, v, w)$ with components along $(x, y, z)$, the pressure $p$, the density $\rho$ ( $\rho_{o}$ is a reference value), and the (potential) temperature $T$. Other quantities in (2) are the time $t$, the horizontal gradient operator $\nabla$, the Coriolis parameter $f$, and the acceleration due to gravity $g$. The vertical turbulent viscosity $\kappa_{m}$ and the vertical turbulent diffusivity $\kappa_{T}$ are obtained from a turbulent closure scheme (Mellor and Yamada 1982) which involves the solution of governing equations for turbulent kinetic energy $\left(q^{2} / 2\right)$ and for $q^{2} l$, where $l$ is a turbulence length scale (Blumberg and Mellor 1987; Mellor 2002). The terms $F_{u}, F_{v}, F_{\mathrm{T}}$ represent horizontal processes at small (subgrid) scales and are parameterized according to Smagorinsky (1963). Equations (2) are complemented with a linear equation of state

$$
\rho=\rho_{o}\left[1-\alpha_{T}\left(T-T_{o}\right)+\alpha_{p}\left(p-p_{o}\right)\right],
$$

where $\left(\alpha_{T}, \alpha_{p}\right)$ are constant coefficients and $\left(T_{o}, p_{o}\right)$ are reference values (Table 1 ).

The governing equations (2) are expressed in $\sigma$ coordinates, where $\sigma=(z-\eta) /(h+\eta)$, and are solved numerically using a "mode splitting" technique (Blumberg and Mellor 1987; Mellor 2002). This technique allows the calculation of the free surface elevation at relatively small computational cost through a separate treatment of slow motions (internal mode) and fast motions (external mode). For future reference, a quantity averaged from the bottom $(\sigma=-1)$ to the surface $(\sigma=0)$ is represented with an overbar, for example, $\bar{u}$ is the $x$ component of the velocity for the external mode.

\section{c. Initial conditions}

The initial conditions of the model correspond to a jet in thermal wind balance along the shelf edge (Fig. 2). The initial velocity field for the internal mode is given by

$$
u=0 \quad \text { and } \quad v=v_{\text {jet }}(x, z),
$$

where
TABLE 1. Parameters of the ocean model. Dimensionless quantities are denoted by 1 .

\begin{tabular}{llcc}
\hline \hline & & Value & Units \\
\hline \multicolumn{3}{c}{ Physical parameters } & \\
$\rho_{o}$ & Reference density & 1025 & $\mathrm{~kg} \mathrm{~m}^{-3}$ \\
$T_{o}$ & Reference temperature & 14 & ${ }^{\circ} \mathrm{C}$ \\
$p_{o}$ & Reference pressure & 0 & $\mathrm{~Pa}$ \\
$c$ & Speed of sound $\left(1 / c^{2}=\partial \rho / \partial p\right)$ & 1500 & $\mathrm{~m} \mathrm{~s}^{-1}$ \\
$\alpha_{T}$ & Coefficient for temperature & $2 \times 10^{-4}$ & ${ }^{\circ} \mathrm{C}^{-1}$ \\
$\alpha_{p}$ & Coefficient for pressure & $1 /\left(\rho_{o} c^{2}\right)$ & $\mathrm{Pa}^{-1}$ \\
$g$ & Acceleration due to gravity & 9.806 & $\mathrm{~m} \mathrm{~s}^{-2}$ \\
$f$ & Coriolis parameter & $10^{-4}$ & $\mathrm{~s}^{-1}$ \\
$C$ & Smagorinsky coefficient & 0.5 & 1 \\
$\kappa_{m, o}$ & Background vertical viscosity & 0 & $\mathrm{~m}^{2} \mathrm{~s}^{-1}$ \\
$\kappa_{T, o}$ & Background vertical diffusivity & 0 & $\mathrm{~m}^{2} \mathrm{~s}^{-1}$ \\
$P_{r}$ & Turbulent Prandtl number & 5 & 1 \\
$C_{d}$ & Bottom drag coefficient & 0.003 & 1 \\
& & & \\
$\Delta t_{E}$ & Time step (external mode) & 5 & $\mathrm{~s}$ \\
$\Delta t_{I}$ & Time step (internal mode) & 150 & $\mathrm{~s}$ \\
$\Delta s$ & Step interval for advective terms & 5 & 1 \\
$h_{\text {max }}$ & Maximum depth in radiation condition & 200 & $\mathrm{~m}$ \\
$u_{\mathrm{max}}$ & Maximum velocity for CFL violation & 100 & $\mathrm{~m} \mathrm{~s}^{-1}$ \\
$c$ & Constant of Asselin filter & 0.05 & 1 \\
$\alpha_{w}$ & Weight for surface slope term ${ }^{\mathrm{b}}$ & 0 & 1 \\
\hline & & & \\
\hline
\end{tabular}

${ }^{\text {a }}$ Step interval during which advective terms of the external mode are not updated.

${ }^{\mathrm{b}}$ Weight used for surface slope terms in the external mode equations.

$$
v_{\text {jet }}(x, z)=v_{o} \exp \left[-\sigma_{x}\left(x-x_{m}\right)^{2}\right] \exp \left(\sigma_{z} z\right) .
$$

Here $\sigma_{x}=4 \ln \left(v_{o} / 0.1 \mathrm{~m} \mathrm{~s}^{-1}\right) / x_{d}^{2}$ and $\sigma_{z}=\ln \left(v_{o} / 0.1 \mathrm{~m} \mathrm{~s}^{-1}\right) /$ $z_{d}$ are determined such that the $0.1 \mathrm{~m} \mathrm{~s}^{-1}$ isotach falls at a distance $x_{d} / 2$ from the jet axis at $x_{m}$ and at a depth $z_{d}$ from $z=0$. The jet width $x_{d}$ and the jet depth $z_{d}$ are set equal to $20 \mathrm{~km}$ and $70 \mathrm{~m}$, respectively. The expression (5) with these values for $\left(x_{d}, z_{d}\right)$ was used to represent the velocity field of the shelfbreak jet of the MAB in linear stability analyses (Lozier et al. 2002; Lozier and Reed 2005). Here, the maximum velocity of the jet is set equal to $v_{o}=-0.25 \mathrm{~m} \mathrm{~s}^{-1}$, within the observational range of the mean geostrophic velocity south of Nantucket (Linder and Gawarkiewicz 1998).

The initial velocity field for the external mode $(\bar{u}, \bar{v})$ is obtained from the vertical average of (4) with $v_{\text {jet }}(x, z)$ given by (5). The initial field of surface elevation $\eta$ is then derived geostrophically from the initial field of $(\bar{u}, \bar{v})$.

The initial temperature field is obtained from the integration of $\partial T / \partial x=\left(f / \alpha_{T} g\right) \partial v / \partial z$ to the offshore boundary at $x=L_{x}$,

$$
T(x, z)=T\left(L_{x}, z\right)-\frac{\sigma_{z}}{\sqrt{\sigma_{x}}} \frac{f v_{o}}{\alpha_{T} g} e^{\sigma_{z} z} \int_{\zeta}^{\zeta_{B}} e^{-\zeta^{\prime 2}} d \zeta^{\prime} .
$$


Here $\zeta=\sqrt{\sigma_{x}}\left(x-x_{m}\right), \zeta_{B}=\sqrt{\sigma_{x}}\left(L_{x}-x_{m}\right)$, and the integral is evaluated from the difference between two error functions. The initial temperature at the offshore boundary is taken as

$$
T\left(L_{x}, z\right)=T_{o}+\left(\frac{\partial T}{\partial z}\right)_{o} z
$$

with $T_{o}=20^{\circ} \mathrm{C}$ and $(\partial T / \partial x)_{o}=0.05^{\circ} \mathrm{Cm}^{-1}$. The resulting vertical density distribution approximates average conditions from April to May seaward of the Nantucket Shoals (Linder and Gawarkiewicz 1998). The initial temperature field assumed in the model shows isotherms sloping upward in the offshore direction, that is, the jet is retrograde (Fig. 2).

Finally, the initial values of the turbulence variables $\left(q^{2}, q^{2} l\right)$ are set to zero. Notice that no noise is applied to initialize the model. Thus, any instability of the modeled flow should arise, not from the amplification of perturbations that are initially prescribed, but from the fact that the initial conditions of the model are not an exact solution of the equations of motion as represented in the numerical model and supplemented by the boundary conditions described below.

\section{d. Boundary conditions}

The ocean model is subjected to a set of conditions at the horizontal and vertical boundaries of the domain. Different conditions are imposed at the coast, which is a closed boundary, and at the other three lateral boundaries, which are all open. Conditions imposed at the open boundaries of regional models are intended to prevent perturbations generated within the domain from reflecting at the boundaries and contaminating the interior solution. Numerous combinations of open boundary conditions have been experimented for this work. The selected set of boundary conditions is briefly described below; details about their numerical implementation can be found in Mellor (2002). For convenience, the velocity component normal (tangent) to the boundary is referred below to as $u_{n}$ or $\bar{u}_{n}\left(u_{t}\right.$ or $\left.\bar{u}_{t}\right)$.

\section{1) Horizontal BOUNDARIES: 3D FIELDS}

Conditions of no-normal flow and no slip are specified at the coast, that is, respectively,

$$
u_{n}=0 \quad \text { and } \quad u_{t}=0 \quad \text { at } \quad x=0 .
$$

At the offshore, southern, and northern boundaries, the velocity normal to the boundary is calculated from a radiation condition, whereas the velocity tangent to the boundary is set to zero:

$$
\begin{aligned}
& \frac{\partial u_{n}}{\partial t} \pm c_{i} \frac{\partial u_{n}}{\partial n}=0 \quad \text { and } \quad u_{t}=0 \quad \text { at } \\
& x=L_{x} \quad \text { and } \quad y=0, L_{y} .
\end{aligned}
$$

Here $n$ is the coordinate normal to the boundary and $c_{i}$ is a speed for the internal mode, derived from the water depth at the boundary and a maximum depth $h_{\max }$ (Mellor 2002).

The condition on temperature is a radiation condition at all boundaries,

$$
\frac{\partial T}{\partial t} \pm u_{n} \frac{\partial T}{\partial n}=0 \quad \text { at } \quad x=0, L_{x} \quad \text { and } \quad y=0, L_{y} .
$$

If $u_{n}$ corresponds to motion directed outward of the domain, then (10) is augmented to include vertical advection, $w \partial T / \partial z$, expressed in $\sigma$ coordinates. The conditions on $\left(q^{2}, q^{2} l\right)$ are similar to that on $T$,

$$
\begin{aligned}
& \frac{\partial\left(q^{2}, q^{2} l\right)}{\partial t} \pm u_{n} \frac{\partial\left(q^{2}, q^{2} l\right)}{\partial n}=0 \quad \text { at } \\
& x=0, L_{x} \quad \text { and } \quad y=0, L_{y},
\end{aligned}
$$

except that vertical advection is omitted.

\section{2) HorizOnTAL BOUNDARIES: 2D FIELDS}

Conditions of no-normal flow and no slip are prescribed for the depth-averaged velocities at the coast:

$$
\bar{u}_{n}=0 \quad \text { and } \quad \bar{u}_{t}=0 \quad \text { at } \quad x=0 .
$$

At the offshore and northern boundaries, a relationship between surface elevation and velocity normal to the boundary is specified from a radiation condition (Flather 1976), whereas the velocity along the boundary vanishes:

$$
\begin{gathered}
\bar{u}_{n}=\bar{u}_{n, *}+\sqrt{\frac{g}{h}}\left(\eta-\eta_{*}\right) \quad \text { and } \quad \bar{u}_{t}=0 \text { at } \\
x=L_{x} \text { and } y=L_{y} .
\end{gathered}
$$

The depth-averaged velocity $\bar{u}_{n, *}$ and the surface elevation $\eta_{*}$ are set equal to their initial values (section $2 \mathrm{c}$ ). Finally, at the southern boundary, the velocity normal to the boundary is obtained from a radiation condition similar to (9), while the velocity along the boundary vanishes,

$$
\frac{\partial \bar{u}_{n}}{\partial t}-c_{e} \frac{\partial \bar{u}_{n}}{\partial n}=0 \quad \text { and } \quad \bar{u}_{t}=0 \quad \text { at } \quad y=0,
$$

where $c_{e}=\sqrt{g h}$ is the speed of the external mode at the boundary. 


\section{3) Vertical boundaries}

Kinematic conditions are specified on the flow at the surface and at the bottom,

$$
\begin{array}{ll}
w=\frac{\partial \eta}{\partial t}+\mathbf{u}_{h} \cdot \nabla \eta & \text { at } \quad z=\eta(x, y, t), \\
w=-\mathbf{u}_{h} \cdot \nabla h & \text { at } \quad z=-h(x),
\end{array}
$$

where $\mathbf{u}_{h}=(u, v)$ is the horizontal velocity. No wind stress is prescribed at the surface, while a shear stress is imposed at the bottom,

$$
\begin{aligned}
& \rho_{o} \kappa_{m} \frac{\partial \mathbf{u}_{h}}{\partial z}=0 \quad \text { at } \quad z=\eta(x, y, t), \\
& \rho_{o} \kappa_{m} \frac{\partial \mathbf{u}_{h}}{\partial z}=\tau_{b} \quad \text { at } \quad z=-h(x) .
\end{aligned}
$$

The bottom stress is given by

$$
\boldsymbol{\tau}_{b}=\rho_{o} C_{d}\left|\mathbf{u}_{h, b}\right| \mathbf{u}_{h, b},
$$

where $C_{d}$ is a drag coefficient and $\mathbf{u}_{h, b}$ is the horizontal velocity at the bottom (the grid point nearest to the bottom). No heat flux is prescribed at the surface and at the bottom,

$$
\kappa_{T} \frac{\partial T}{\partial z}=0 \quad \text { at } \quad z=\eta(x, y, t),-h(x) .
$$

Finally, in the absence of surface wind stress, the turbulence variables $\left(q^{2}, q^{2} l\right)$ are set to zero both at the surface and at the bottom,

$$
\left(q^{2}, q^{2} l\right)=0 \quad \text { at } \quad z=\eta(x, y, t),-h(x) .
$$

The complete omission of surface forcing implies that the modeled variability will stem exclusively from the instability of the shelfbreak jet.

\section{e. Method of solution}

The differential equations of the model are solved using finite differences on a staggered $\mathrm{C}$ grid (Blumberg and Mellor 1987; Mellor 2002). The horizontal resolution of the grid is $1 \mathrm{~km}$ in both directions $(x, y)$, and the number of vertical levels amounts to 25 with increasing resolution near the bottom (five "logarithmic layers"). The finite-difference forms of the governing equations (2) are second-order accurate in space and time, and conserve mass, momentum, temperature, and energy (Blumberg and Mellor 1987). Unless stipulated otherwise, the model parameters take the values listed in Table 1.

\section{f. Particle transport}

The Lagrangian motion in the simulated flow is revealed from the trajectories of fluid particles. The particle transport equation is

$$
\frac{\mathrm{d} \mathbf{r}_{i}}{\mathrm{~d} t}=\mathbf{u}\left(\mathbf{r}_{i}, t\right)
$$

where $\mathbf{r}_{i}$ is the position of the $i$ th particle and $\mathbf{u}\left(\mathbf{r}_{i}, t\right)$ is the fluid velocity at position $\mathbf{r}_{i}$ and time $t$. Particle transport is calculated in "real time," that is, using the velocity field at each time step and not stored fields with reduced temporal resolution. Different approaches to obtain $\mathbf{u}$ at the particle locations and to integrate (20) have been applied and yield similar results (see appendix for details).

\section{Results}

\section{a. Instability of shelfbreak front}

The ocean model is integrated numerically for a period of 150 days from the initial conditions described in section $2 \mathrm{c}$ and subjected to the boundary conditions described in section $2 \mathrm{~d}$. The evolution of the surface temperature field shows that the shelfbreak front becomes unstable over the course of the integration (Fig. 3). The surface isotherms, which are initially straight and aligned with isobaths, exhibit noticeable fluctuations, first in the northern part of the domain and then over the entire length of the shelf break. The isotherm fluctuations grow with time, leading to the appearance of eddies, particularly on the offshore side of the eddying jet. Eventually, the surface expression of the original front remains apparent only in the northern part of the domain; elsewhere along the slope the front has metamorphosed into a complex eddy field. Notice in particular the eddy dipole, or dipolar vortex, located in the deep basin at $x \sim 350 \mathrm{~km}$ at the end of the simulation.

The vertical component of relative vorticity $\zeta=$ $\partial v / \partial x-\partial u / \partial y$ provides additional information about the development of the eddying flow (Fig. 4). The relative vorticity of the initial flow is only due to the cross-slope variation in the along-slope velocity, $\partial v / \partial x$ [(4)]. Thus, the initial flow is entirely anticyclonic on the inshore side of the jet axis $(\partial v / \partial x<0$ at $x<200 \mathrm{~km})$ and entirely cyclonic on the offshore side of the axis $(\partial v / \partial x>0$ at $x>200 \mathrm{~km})$. In the initial flow, the relative vorticity presents amplitude maxima equal to about 0.2 the value of the planetary vorticity $f$ (not shown). Over the course of the integration, the relative vorticity reaches values of $O(f)$, indicating that 

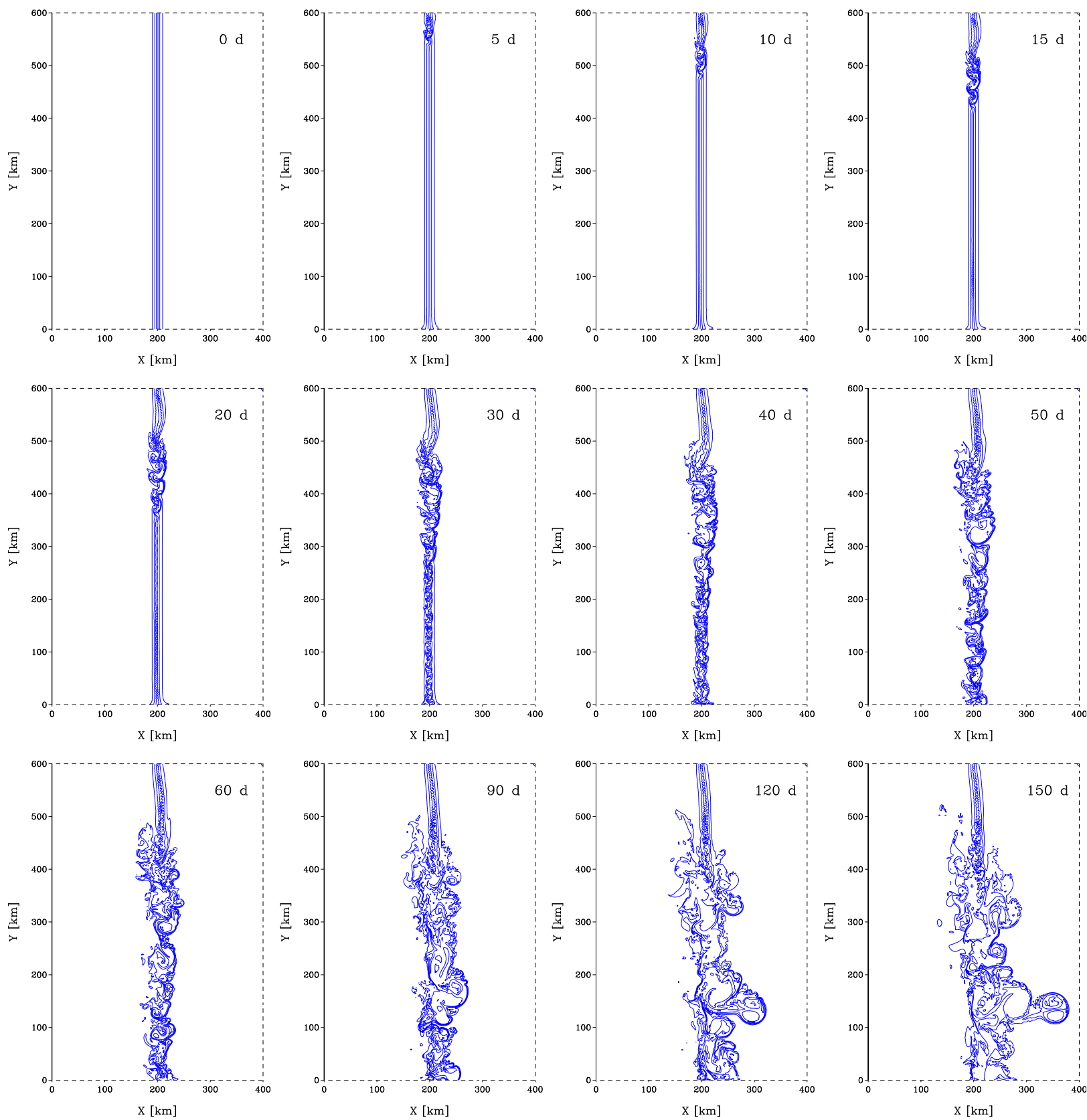

FIG. 3. Evolution of surface temperature during the model integration (contour interval $=0.5^{\circ} \mathrm{C}$ ). Panels of the first, second, and third rows show distributions that are 5, 10, and 30 days apart, respectively.

nonlinearity due to momentum advection is important in the flow evolution (Fig. 4). A regular sequence of cyclones and anticylones is simulated on each side of the jet axis and propagates southward along the shelf break. Ultimately, the surface flow presents thin and contorted filaments of negative and positive vorticity, on each side of the jet axis and in regions where the fluid was initially quiescent. A similar result appears in previous numerical simulations of frontal instability with comparable $(0.5-2 \mathrm{~km})$ horizontal resolution (e.g., Spall 1995; Mahadevan and Tandon 2006; Klein et al. 2008; Shcherbina et al. 2013).

\section{b. Kinetic and potential energies}

It is instructive to consider the evolution of the kinetic energy and (available) potential energy of the flow. Following earlier model studies of coastal dynamics (e.g., Brink 2016a), dynamical variables are decomposed 

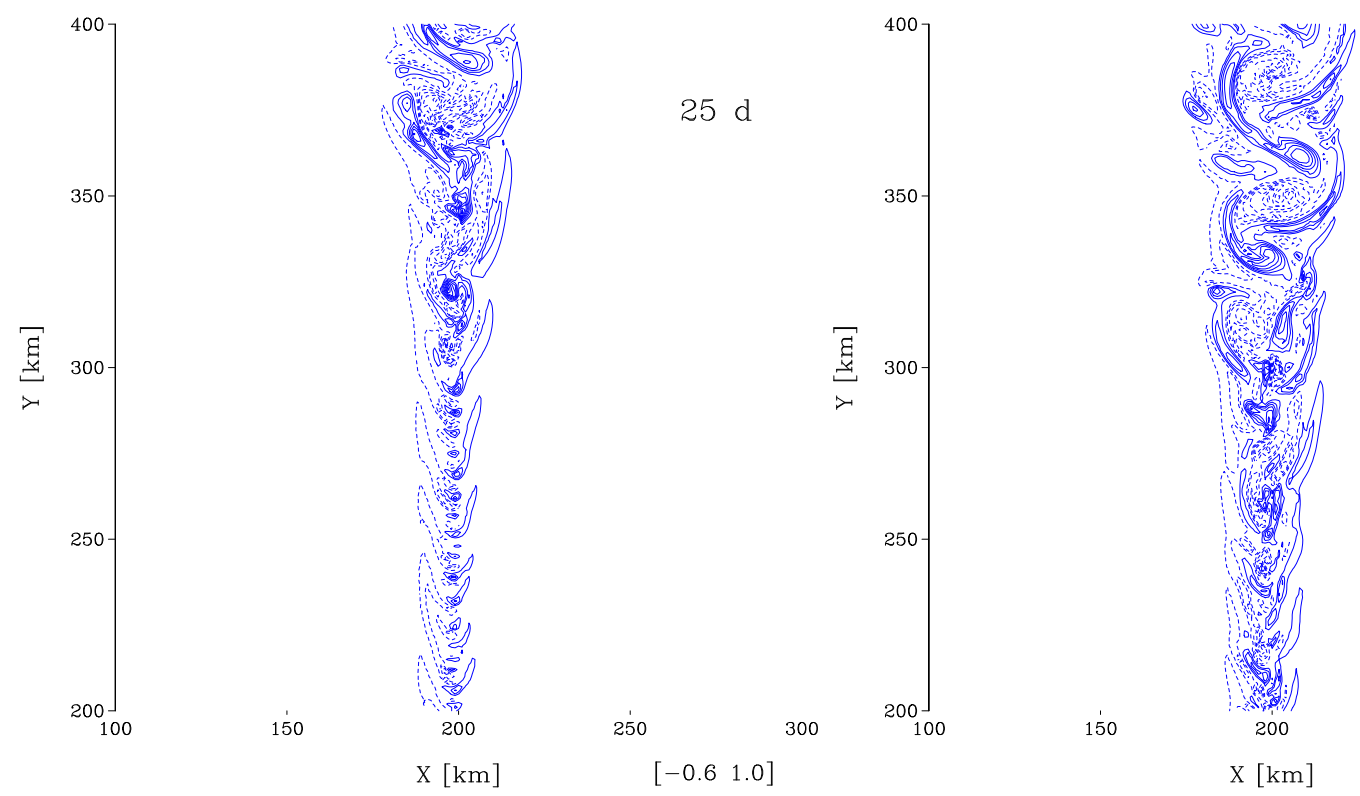

$30 \mathrm{~d}$
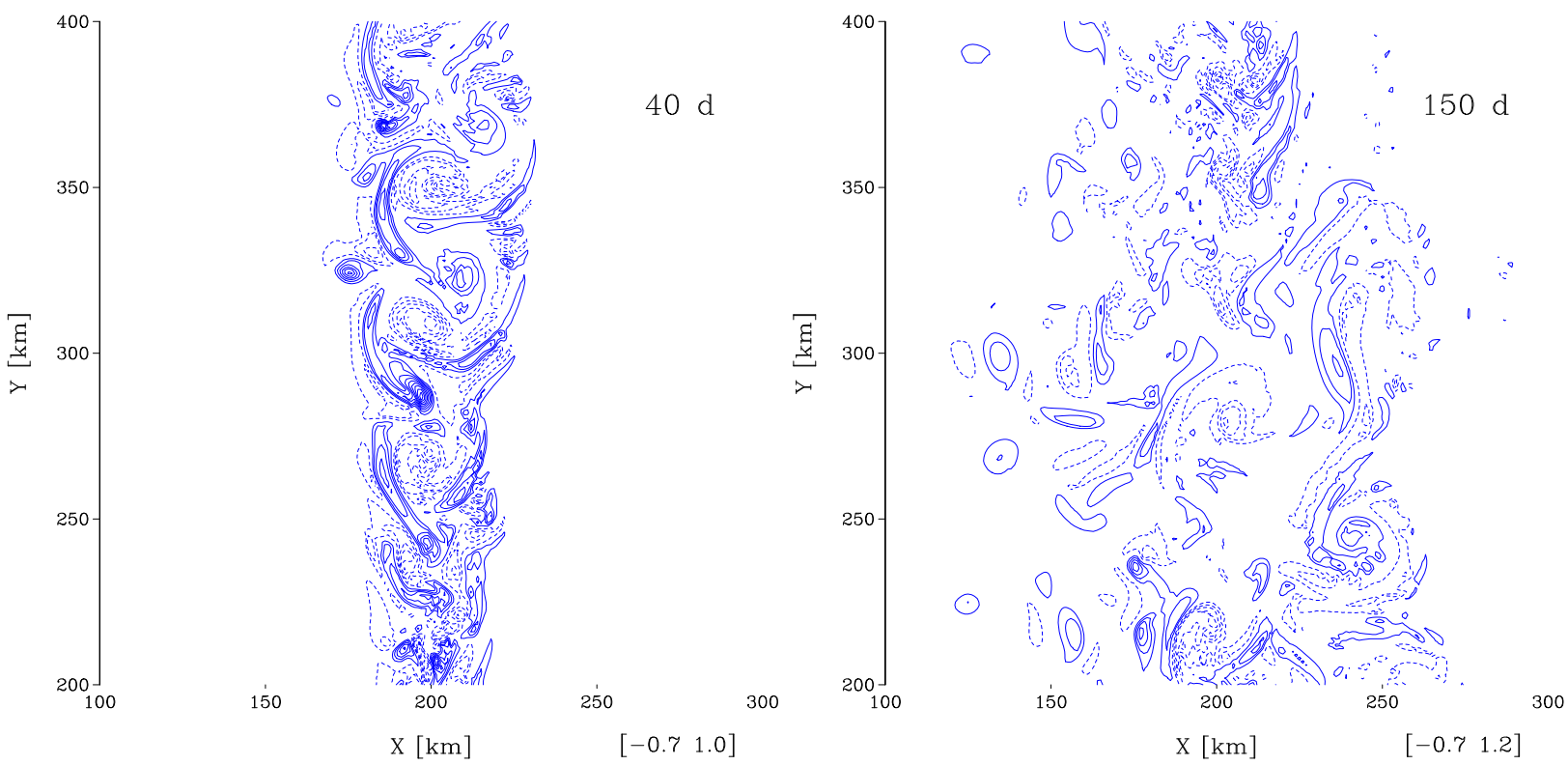

FIG. 4. Evolution of relative vorticity (vertical component normalized to $f$ ) at a depth of $10 \mathrm{~m}$ in a subregion of the model domain. Positive (negative) values are shown with solid (dashed) lines. The range of displayed values appears between square brackets at the bottom right of each panel.

into an along-slope average and a deviation, for example, $u=\{u\}+u^{\prime}$, where

$$
\{u\}=\frac{1}{L_{y}} \int_{0}^{L_{y}} u d y .
$$

With this notation, the domain averages of mean kinetic energy (MKE) and eddy kinetic energy (EKE) are, respectively,

$$
\begin{aligned}
& \operatorname{MKE}(t)=\frac{1}{A} \int_{0}^{L_{x}} \int_{-h(x)}^{0} \frac{\{u\}^{2}+\{v\}^{2}}{2} d z d x, \\
& \operatorname{EKE}(t)=\frac{1}{A} \int_{0}^{L_{x}} \int_{-h(x)}^{0} \frac{\left\{u^{\prime 2}\right\}+\left\{v^{2}\right\}}{2} d z d x,
\end{aligned}
$$

where $A$ is the cross-sectional area of the domain. Potential energy is defined using as a background state an ocean at rest whose density distribution is approximated 


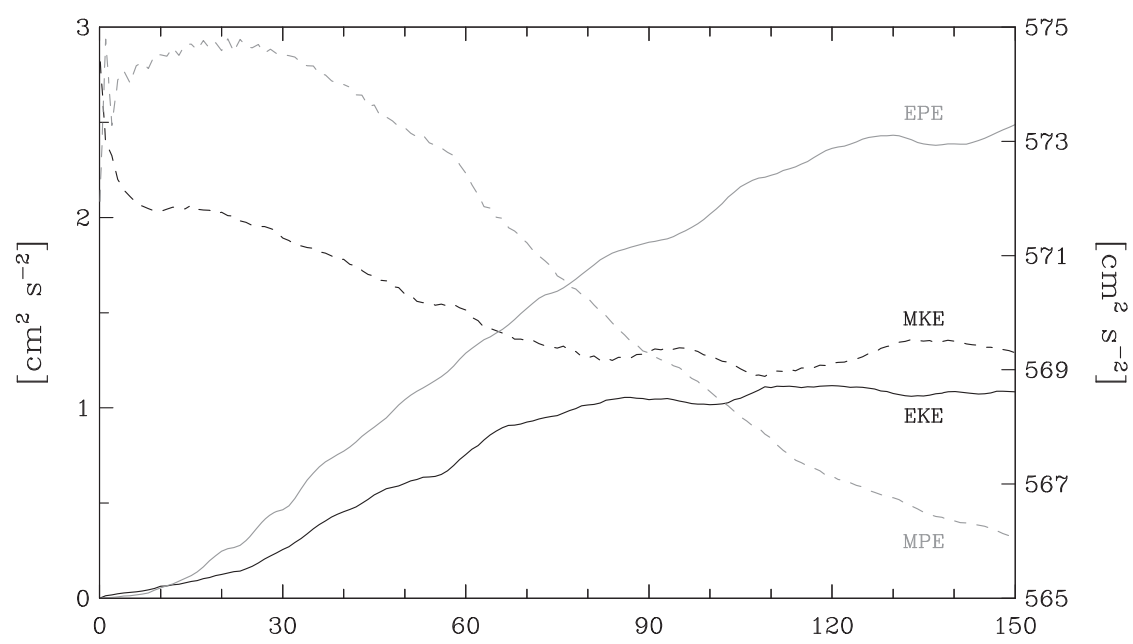

FIG. 5. Evolution of MKE (dashed black line), EKE (solid black), MPE (dashed gray), and EPE (solid gray) during the model integration. MKE, EKE, and EPE are plotted with the left scale, whereas MPE is plotted with the right scale.

by the initial density profile at the offshore boundary $x=$ $L_{x}$ (e.g., Xue and Bane 1997; Zhang and Gawarkiewicz 2015). With this convention, the domain averages of mean potential energy (MPE) and eddy potential energy (EPE) are computed from, respectively,

$$
\begin{aligned}
& \operatorname{MPE}(t)=\frac{1}{A} \int_{0}^{L_{x}} \int_{-h(x)}^{0} \frac{g\{\tilde{\rho}\}^{2}}{2 \rho_{o}\left(-\partial \rho_{b} / \partial z\right)} d z d x, \\
& \operatorname{EPE}(t)=\frac{1}{A} \int_{0}^{L_{x}} \int_{-h(x)}^{0} \frac{g\left\{(\tilde{\rho})^{2}\right\}}{2 \rho_{o}\left(-\partial \rho_{b} / \partial z\right)} d z d x,
\end{aligned}
$$

where $\tilde{\rho}=\rho-\rho_{b}$ is the difference between the simulated density and the density of the background state.

It is seen that mean kinetic energy decreases and eddy kinetic energy increases over the course of the numerical integration (Fig. 5a). The EKE becomes close to MKE and remains roughly constant after about 90 days, indicating that the eddying motions significantly contribute to total kinetic energy and are statistically steady during the last 60 days of the simulation. Similarly, mean potential energy decreases and eddy potential energy increases with time, although MPE remains larger than EPE by at least two orders of magnitude during the simulation (Fig. 5a). A detailed investigation of the energetics of the simulated flow is beyond the scope of this paper; perturbation analyses suggest that the primary mechanisms responsible for the emergence of along-slope fluctuations are baroclinic and/or barotropic instabilities (e.g., Lozier et al. 2002).

\section{c. Horizontal and temporal scales}

In this section, we determine horizontal and temporal scales of variability of the eddying flow in the numerical simulation of frontal instability. Consider first the determination of horizontal scale. A visual inspection of the surface temperature fields suggests a scale of a few tens of kilometers for eddies present along the offshore side of the flow for $t \geq 90$ days (Fig. 3). A more objective measure of the dominant scale of along-slope fluctuations can be obtained from the along-slope covariance of the cross-slope velocity (e.g., Brink and Seo 2016). Here correlograms of $\bar{u}$ at the shelf break (at $x=200 \mathrm{~km}$ ), with spatial separation along the slope $\Delta y$ as lag variable, are calculated for (i) the region from $y=100$ to $400 \mathrm{~km}$, where the influence of cross-margin boundaries on the flow should be relatively small, and (ii) the time interval from $t=90$ to 150 days, when EKE is relatively constant (Fig. 5a). The correlogram obtained by averaging autocorrelation coefficients from $t=90$ to 150 days displays a monotonic decrease with spatial separation along the slope and a zero crossing at $\Delta y=10-11 \mathrm{~km}$ (Fig. 6a). Thus, positive or negative deviations of $\bar{u}$ near the shelf edge persist on average over a distance of $\sim 10 \mathrm{~km}$ in the along-slope direction.

Consider then the determination of a temporal scale of shelf-basin exchange. Correlograms of $\bar{u}$ with time difference $\Delta t$ as lag variable are calculated for the region from $y=100$ to $400 \mathrm{~km}$ and the time interval from $t=90$ to 150 days. We find that the correlogram obtained by averaging autocorrelations from $y=100$ to $400 \mathrm{~km}$ displays a zero crossing at $\Delta t=4-5$ days (Fig. 6b), that is, positive or negative deviations of $\bar{u}$ at the shelf break persist on average over a time interval of a few days.

\section{d. Lagrangian motion}

In this section, we describe the transport of fluid parcels in the eddying flow resulting from the instability 

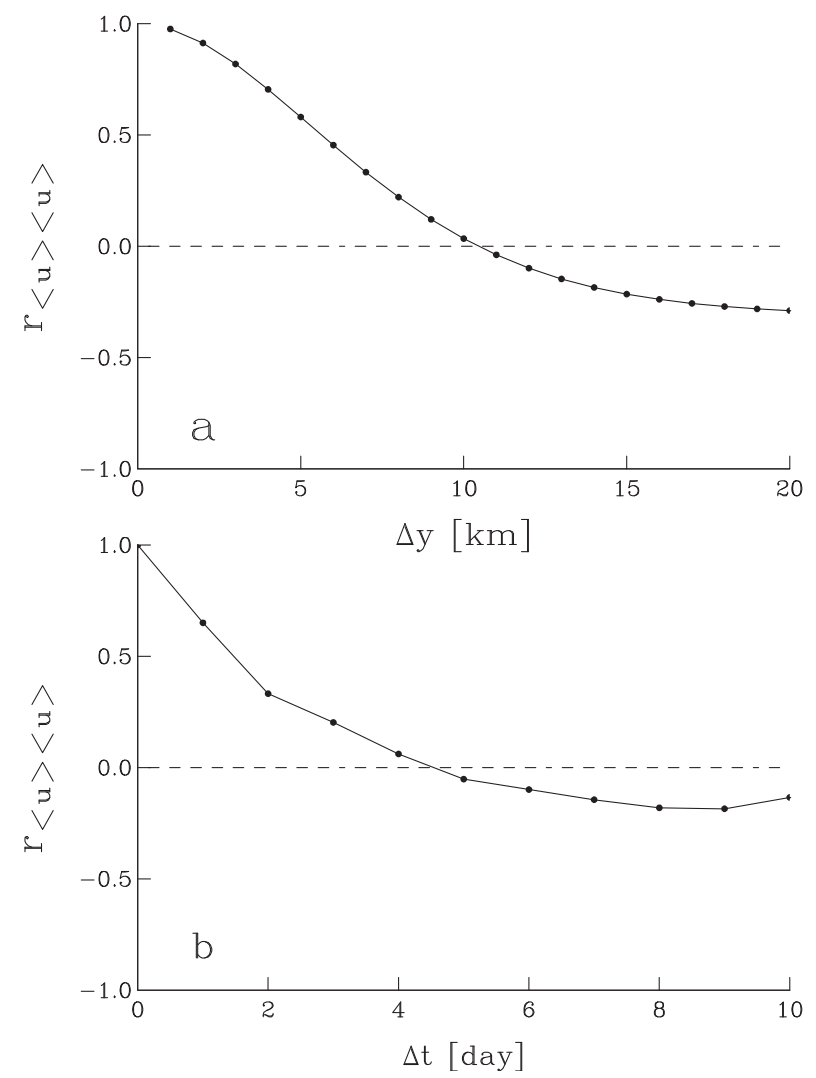

FIG. 6. Correlograms of $\bar{u}$ at the shelf break $(x=200 \mathrm{~km})$. (a) Autocorrelation with spatial separation along the slope as lag variable. The autocorrelation coefficients for $t=90,91, \ldots, 150$ days have been averaged to produce the figure. (b) Autocorrelation with time difference as lag variable. The autocorrelation coefficients for $y=100,101, \ldots, 400 \mathrm{~km}$ have been averaged to produce the figure.

of the shelfbreak jet. The equation of particle motion (20) is integrated for particles which are introduced in different regions of the model domain. In all reported calculations, particles are seeded when EKE becomes approximately steady (at $t=90$ days), and their movement is calculated till the end of the numerical integration ( $t=150$ days). The distribution of eddy kinetic energy $\left(\left\{u^{\prime 2}\right\}+\left\{v^{2}\right\}\right) / 2$ averaged over this time interval shows maxima near the surface at the shelf break (Fig. 7). Motivated by this result, the transport of particles originating from the surface layer is investigated first; the motion of particles initially located near the bottom is studied next.

The cross-slope spreading of particles released in a given region is characterized and quantified using the concept of relative dispersion (e.g., LaCasce 2008),

$$
D_{x}(t)=\frac{1}{N} \sum_{i=1}^{N}\left[\Delta x_{i}(t)-\Delta X(t)\right]^{2}
$$

Here $N$ is the number of released particles, $\Delta x_{i}(t)$ is the displacement of the $i$ th particle in the cross-slope direction relative to its initial position, and $\Delta X(t)$ is the displacement of the "center of mass" of the particles in this direction, that is, $\Delta X(t)=(1 / N) \sum_{i=1}^{N} \Delta x_{i}(t)$. Interestingly, $D_{x}(t)$ can also be expressed as (LaCasce 2008),

$$
D_{x}(t)=\frac{1}{2 N(N-1)} \sum_{i \neq j}^{N}\left[x_{i}(t)-x_{j}(t)\right]^{2} .
$$

Thus, the displacement variance of particles is proportional to the mean square separation between particle pairs. Notice that $D_{x}(t)$ is only computed for the set of particles which do not reach the boundaries of the domain during the time interval from $t=90$ to 150 days (appendix).

The evolution of $D_{x}$ yields information about the spreading regime (e.g., Vallis 2006; Rypina et al. 2016). Differences in the motion of particles situated at different locations are obviously due to differences in the velocity at these locations. If differences in the velocity at different locations are sufficiently small, $D_{x} \propto t^{2}$ and the spreading regime is "ballistic." If the velocity of a particle is uncorrelated from that at neighboring locations, $D_{x} \propto t$ and the spreading regime is "diffusive." Clearly, other regimes of particle dispersion are possible. In his review of Lagrangian observations, LaCasce (2008) reported that, although results based on pairs of particles are not wellestablished yet, pair separation appears to grow exponentially in time below the deformation radius, consistent with an enstrophy cascade. At larger scales, the behavior is less clear $\left(D_{x} \propto t^{3}\right)$, indicative of either an energy cascade or shear dispersion (LaCasce 2008).

\section{1) DISPERSION OF JET PARTICLES}

In this section, we describe the cross-slope transport of particles originating from a rectangular region within the initial path of the jet (region B in Fig. 8). This region extends in the cross-slope direction from $x=x_{m}-3 s_{x}$ to $x=x_{m}+3 s_{x}$, where $x_{m}=200 \mathrm{~km}$ and $s_{x}=1 / \sqrt{2 \sigma_{x}}=7.4$ $\mathrm{km}$, that is, over a strip which carries $99 \%$ of the initial jet volume transport per unit depth [(5)]. This region extends in the along-slope direction from $y=100$ to $400 \mathrm{~km}$. Particles are released in this region at $t=90$ days and their movements are tracked until $t=150$ days.

It is seen that particles are detrained both onshore and offshore of the initial path of the jet within small-scale structures such as filaments, rings, and eddies (Fig. 9). The fraction of detrained particles is substantial: after 60 days of transport by the eddy field, $28 \%$ of the particles are found on the inshore side of the jet $\left(x<x_{m}-3 s_{x}\right)$ and $32 \%$ of the particles are found on the offshore side of the jet $\left(x>x_{m}+3 s_{x}\right)$. Thus, the majority of the particles have 


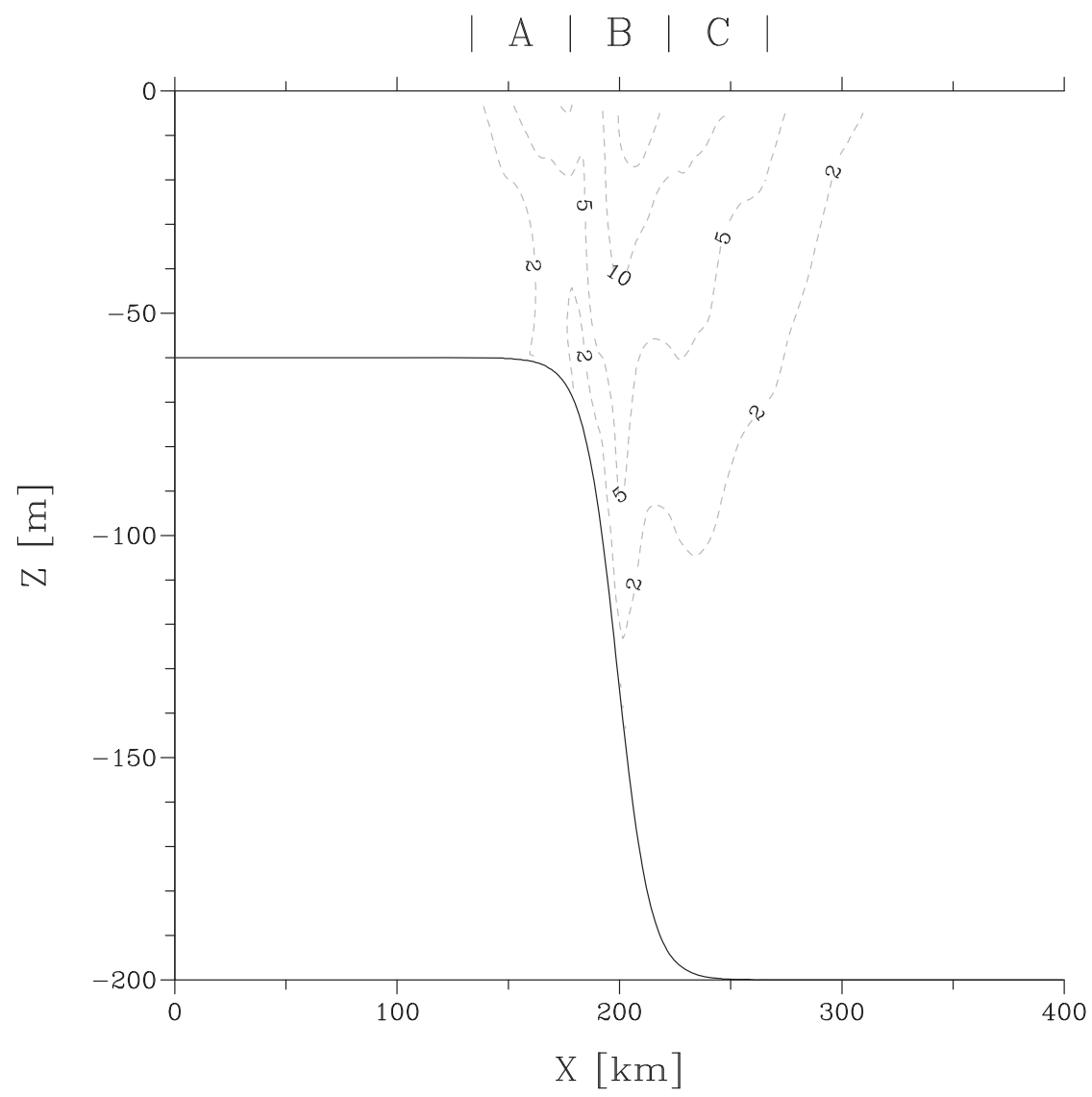

FIG. 7. Cross-slope distribution of eddy kinetic energy, EKE $=\left(\left\{u^{2}\right\}+\left\{v^{\prime 2}\right\}\right) / 2$, averaged from $y=100$ to $400 \mathrm{~km}$ and from $t=90$ to 150 days (daily values). The contour interval is $5 \mathrm{~cm}^{2} \mathrm{~s}^{-2}$ for EKE $>5 \mathrm{~cm}^{2} \mathrm{~s}^{-2}$.

left the initial path of the jet under the action of the eddy field produced from the jet instability. While individual particles follow intricate paths, the mean square separation tends to increase linearly in time (circles in Fig. 10), with $D_{x} \sim t^{1.18}$ (Table 2). This result suggests that particle transport is approximately diffusive: the spatial and temporal scales of the eddy field are sufficiently short that particles in a pair generally experience different velocities over a 2-month period.

\section{2) DISPERSION OF SHELF AND BASIN PARTICLES}

A shelfbreak jet in strict thermal wind balance is a perfect barrier to fluid exchange between the shelf and the open ocean. A question of preeminent interest is the extent to which the instability of the jet can break this constraint and lead to the transport of material between the two regions. Consider first the transport of particles originating from the shelf. Particles are released in a region extending from $x=x_{m}-9 s_{x}$ to $x=x_{m}-3 s_{x}$ and from $y=100$ to $400 \mathrm{~km}$ (region A; Fig. 8). After two months of transport in the eddy field, only a very small fraction $(1 \%)$ of the shelf particles is found on the offshore side of the jet $\left(x>x_{m}+3 s_{x}\right.$; Fig. 11). As for jet particles, the cross-slope dispersion of shelf particles approximately grows linearly in time $\left(D_{x} \sim t^{1.13}\right.$; Table 2), but it is noticeably smaller (cf. pluses with circles in Fig. 10).

Consider then the transport of particles originating from the deep basin. Particles are released on the offshore side of the initial jet in the region extending from $x=x_{m}+3 s_{x}$ to $x=x_{m}+9 s_{x}$ and from $y=100$ to $400 \mathrm{~km}$ (region C; Fig. 8). After two months of transport in the eddying flow, the fraction of particles found on the inshore side of the jet $\left(x<x_{m}-3 s_{x}\right)$ is only $3 \%$ (Fig. 12). This value is comparable to the fraction of shelf particles found on the offshore side of the jet after the same amount of time, indicating that material transport across the jet is limited in both the offshore and inshore directions. The cross-slope dispersion of basin particles tends to increase linearly in time $\left(D_{x} \sim t^{1.22}\right.$; Table 2$)$, as for basin and shelf particles (Fig. 10). However, the cross-slope dispersion of basin particles is several times 


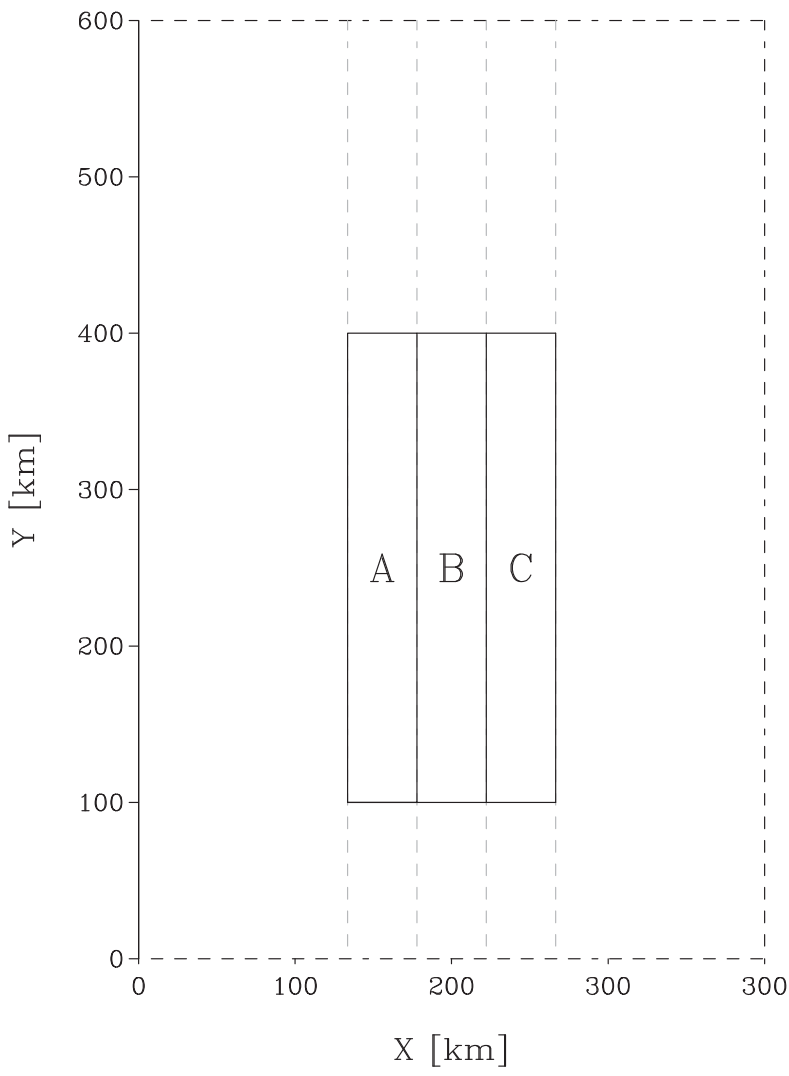

FIG. 8. Model domain and the three regions $(\mathrm{A}, \mathrm{B}, \mathrm{C})$ where particles originate.

greater than that of shelf particles and even exceeds that of jet particles (Fig. 10).

In summary, whereas particle detrainment from the initial path of the jet is important, particle transport across this path is very limited (Table 2). While the transports across the jet of shelf and basin particles are of comparable magnitude, dispersion in the cross-slope direction is noticeably larger for basin particles than for shelf particles. Similar results hold for particles released at middepth, that is, at $z=30 \mathrm{~m}$, which is half the shelf depth (Table 2).

\section{3) DISPERSION OF NEAR-BOTTOM PARTICLES}

In this section, we consider the motion of particles initially located near the bottom on the shelf (region A) or along the slope (region B). Particles are released from the three bottom-most layers (within $2 \mathrm{~m}$ of the bottom) in each of these regions. As for the near-surface and middepth particles, their transport by the eddying flow is calculated from $t=90$ to 150 days.

It is seen that, after 60 days of transport in the eddying jet, a number of near-bottom particles, primarily from region $\mathrm{B}$, are detrained offshore (Fig. 13). Jet particles are detrained seaward over a horizontal distance of $O(100) \mathrm{km}$ within a coherent vortex that separates from the initial path of the jet (Fig. 13b). The fraction of jet particles that are found outside the initial path of the jet after 60 days amounts to only $7 \%$, much less than the fraction of $60 \%$ for near-surface particles (Table 2), a result consistent with the relatively small levels of eddy kinetic energy near the bottom (Fig. 7). The fraction of shelf particles found offshore of the initial path of the jet is even smaller (Table 2). As for near-surface particles, the cross-slope dispersion of near-bottom particles increases monotonically with time (Fig. 14). Whereas the dispersion of shelf particles is approximately diffusive $\left(D_{x} \sim t^{1.29}\right)$, the dispersion of jet particles $\left(D_{x} \sim t^{1.80}\right)$ approaches a ballistic regime (Table 2).

\section{Discussion}

The overall evolution of the simulated shelfbreak front is characterized by a leveling of isotherms (Fig. 15). The available potential energy stored in the cross-slope temperature gradients is released and transferred to the perturbations through the mechanism of baroclinic instability (section 3b). Consistent with the reduced crossslope thermal gradients, the strength of the along-slope jet decreases over the course of the simulation, for example, the maximum amplitude of $v$ averaged from $y=$ 100 to $400 \mathrm{~km}$ and from $t=90$ to 150 days amounts to only about half its initial value (Fig. 16). The changes in the cross-slope thermal gradients (Fig. 15) and alongslope velocity (Fig. 16) indicate that the overall evolution of the flow is frontolytic and accompanied by a migration of the jet core from the surface to below $50 \mathrm{~m}$.

In this section, we first discuss the secondary circulation which develops as a result of the instability of the shelfbreak front. We then elaborate on three salient results of our Lagrangian calculation. A first result is the smallness of material exchange between the shelf and the deep basin: the vast majority of particles do not cross the frontal region over the 2-month period (cf. values of $\phi_{\mathrm{A}}$ and $\phi_{\mathrm{C}}$ in Table 2). A second result is the pronounced asymmetry in the cross-slope spreading of shelf and basin particles: whereas material transport across the initial path of the jet is small in both the offshore and inshore directions, the displacement variance of basin particles is noticeably larger than that of shelf particles (Fig. 10). The final result relates to the role of BBL separation in the seaward export of near-bottom particles (Fig. 13).

\section{a. Secondary circulation}

The instability of a front is known to lead to the development of an ageostrophic secondary circulation in 

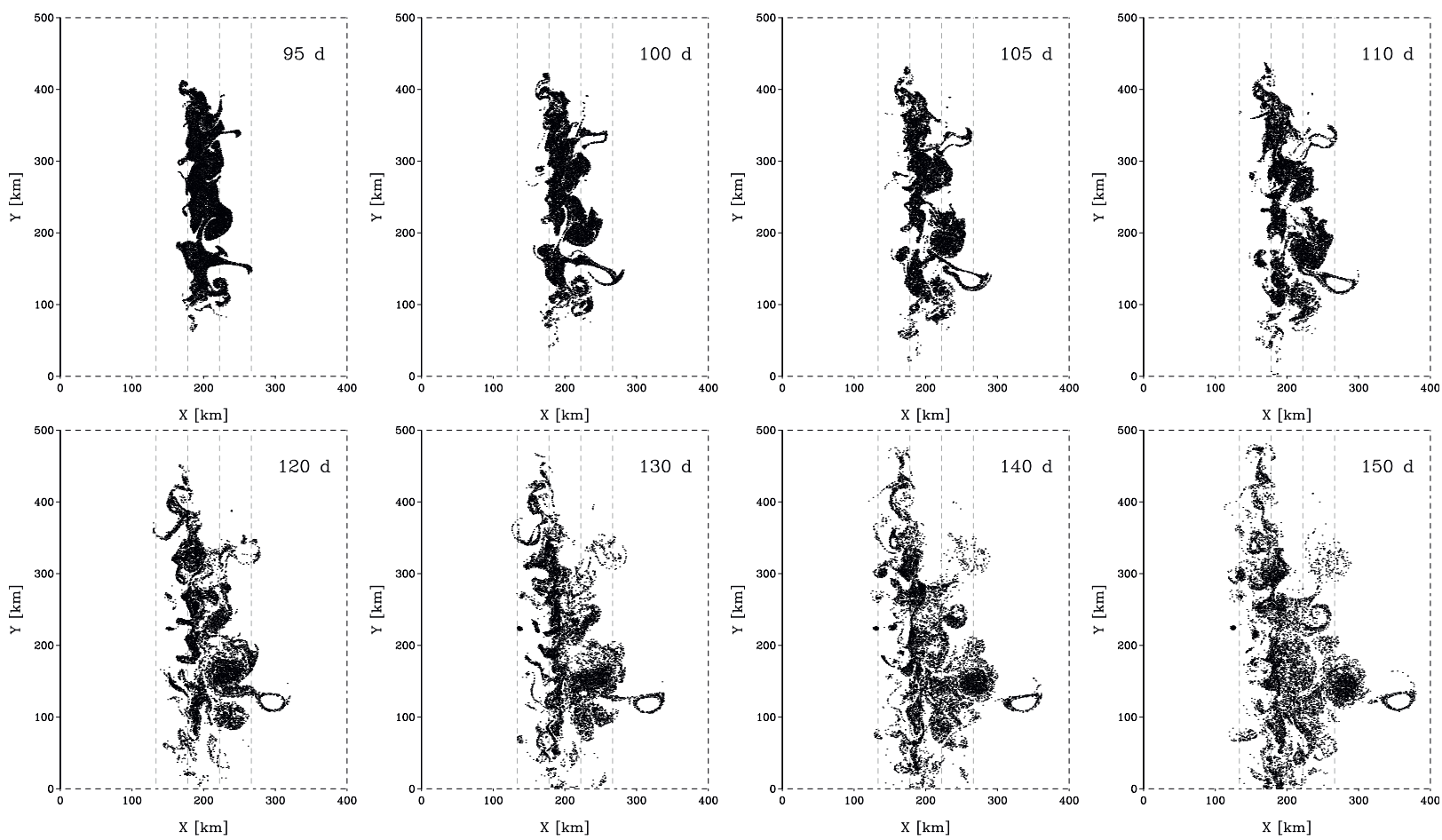

FIG. 9. Evolution of particles originating from the surface layer within the initial jet (region B). In each panel, the dashed gray lines delineate the regions inshore, within, and offshore of the initial jet. Only the particles that do not exit the domain are shown.

the plane normal to the frontal axis (e.g., Thomas et al. 2008). We illustrate the secondary circulation near the shelf edge in our numerical experiment through the cross-slope distribution of the cross-slope velocity averaged from $y=100$ to $400 \mathrm{~km}$ and from $t=90$ to 150 days (Fig. 17). The cross-slope velocities are generally $O(1) \mathrm{mm} \mathrm{s}^{-1}$ (Fig. 17), that is, lower than the along-slope velocities by one to two orders of magnitude

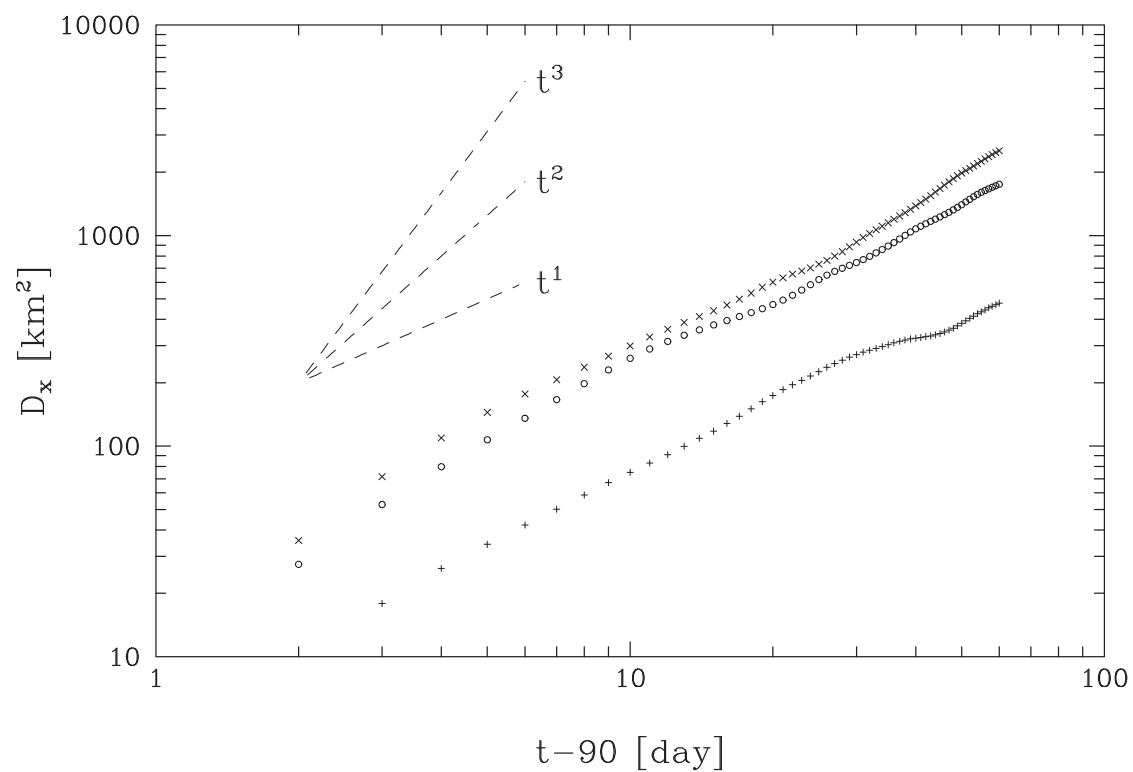

FIG. 10. Evolution of the dispersion of particles released in the surface layer inshore of the initial jet (region $\mathrm{A} ;+$ ), within the initial jet (region $\mathrm{B} ; \mathrm{o}$ ), and offshore of the initial jet (region $\mathrm{C}$; $\mathrm{x}$ ). The three dashed lines show the variations of $D_{x}$ with time in the diffusive regime $\left(D_{x} \propto t^{1}\right)$, the ballistic regime $\left(D_{x} \propto t^{2}\right)$, and a regime indicating either an energy cascade or shear dispersion $\left(D_{x} \propto t^{3}\right)$. 
TABLE 2. Statistics of cross-slope particle spreading. Variables: $\phi_{\mathrm{A}}$ is the percentage of particles released in region A and found after 60 days offshore of the jet, $\phi_{\mathrm{B}}$ is the percentage of particles released in region B and found after 60 days inshore or offshore of the jet, $\phi_{\mathrm{C}}$ is the percentage of particles released in region $\mathrm{C}$ and found after 60 days inshore of the jet, $\hat{b}$ is the least squares estimate of exponent $b$ in $D_{x} \propto t^{b}$, and $n$ is the number of particles.

\begin{tabular}{|c|c|c|c|c|c|c|c|c|c|}
\hline & \multicolumn{3}{|c|}{ Region A } & \multicolumn{3}{|c|}{ Region B } & \multicolumn{3}{|c|}{ Region C } \\
\hline & $\phi_{\mathrm{A}}$ & $\hat{b}$ & $n$ & $\phi_{\mathrm{B}}$ & $\hat{b}$ & $n$ & $\phi_{\mathrm{C}}$ & $\hat{b}$ & $n$ \\
\hline Surface layer & 1 & 1.13 & 12396 & 60 & 1.18 & 12678 & 3 & 1.22 & 12548 \\
\hline $30 \mathrm{~m}$ & 1 & 1.37 & 13002 & 56 & 1.25 & 12119 & 0 & 1.41 & 12120 \\
\hline Bottom layers & 0 & 1.29 & 39499 & 7 & 1.80 & 35017 & & & \\
\hline
\end{tabular}

(Fig. 16). They are onshore for $x \leqq 215 \mathrm{~km}$ and offshore for $x \geqslant 215 \mathrm{~km}$, that is, the cross-slope flow in the upper $\sim 100 \mathrm{~m}$ near the shelf break is diffluent.

The diffluence of the cross-slope flow near the shelf edge is favorable to frontolysis, as shown by considerations on the frontogenetic function,

$$
F=\frac{D}{D t}|\nabla T|,
$$

where $D / D t=\partial / \partial t+\mathbf{u} \cdot \nabla$ is the material derivative (Hoskins 1982). A positive (negative) value of $F$ corresponds to frontogenesis (frontolysis). The function $F$ can also be written as

$$
F=\mathbf{n}_{T} \cdot \nabla\left(\frac{D T}{D t}\right)-\mathbf{n}_{T} \cdot\left(\frac{\partial T}{\partial x} \nabla u+\frac{\partial T}{\partial y} \nabla v+\frac{\partial T}{\partial z} \nabla w\right)
$$

where $\mathbf{n}_{T}=\nabla T /|\nabla T|$ is a unit vector parallel to the temperature gradient. Let us decompose the temperature $T$, the vector $\mathbf{n}_{T}$, and the velocity component $u$ each into an alongshore mean and a fluctuation, for example, $\mathbf{n}_{T}=\left\{\mathbf{n}_{T}\right\}+\mathbf{n}_{T}^{\prime}$, which leads to

$$
-\left\{\frac{\partial T}{\partial x}\left(\mathbf{n}_{T} \cdot \nabla u\right)\right\}=-\frac{\partial\{T\}}{\partial x}\left(\left\{\mathbf{n}_{T}\right\} \cdot \nabla\{u\}\right)-\cdots
$$
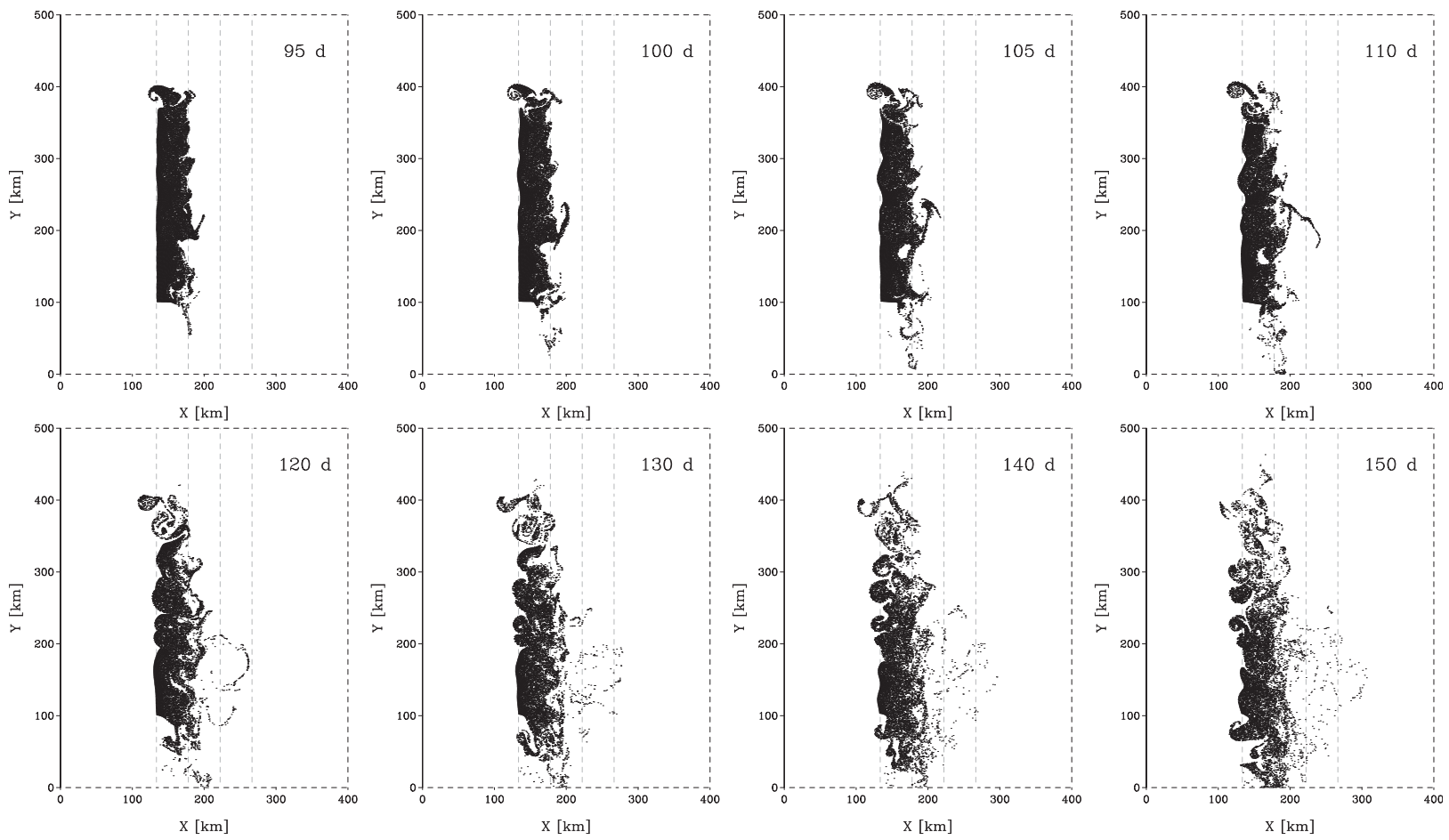

FIG. 11. Evolution of particles originating from the surface layer inshore of the initial jet (region A). In each panel, the dashed gray lines delineate the regions inshore, within, and offshore of the initial jet. Only the particles that do not exit the domain are shown. 

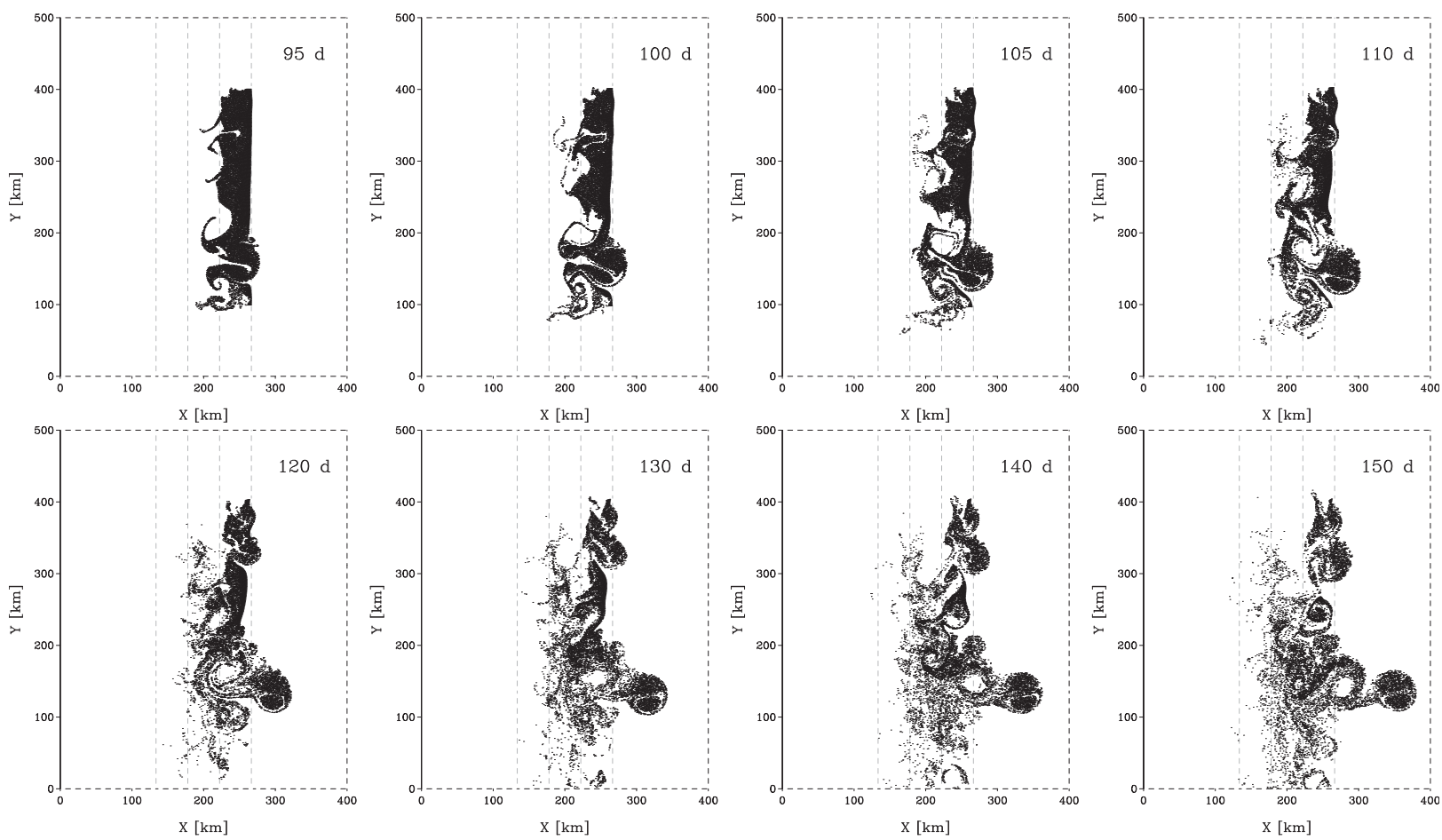

FIG. 12. Evolution of particles originating from the surface layer offshore of the initial jet (region C). In each panel, the dashed gray lines delineate the regions inshore, within, and offshore of the initial jet. Only the particles that do not exit the domain are shown.

For a retrograde jet, $\partial\{T\} / \partial x$ is negative and $\left\{\mathbf{n}_{T}\right\}$ has a positive component in the inshore direction. Thus, if $\{u\}$ increases offshore, as in our numerical simulation (Fig. 17), the term $-\partial\{T\} / \partial x\left(\left\{\mathbf{n}_{T}\right\} \cdot \nabla\{u\}\right)$ is negative and the cross-slope variations of $\{u\}$ are frontolytic (tilted isotherms tend to be separated by diffluence).

Considerations on $\{F\}$ also help to interpret the changes in temperature and in along-slope velocity over the course of the simulation (Figs. 15, 16). The crossslope gradients of $\{u\}$ are the largest in the upper $\sim 50 \mathrm{~m}$ of the water column (Fig. 17). As a result, if the term $-\partial\{T\} / \partial x\left(\left\{\mathbf{n}_{T}\right\} \cdot \nabla\{u\}\right)$ is a dominant contribution to $\{F\}$, the front is expected to be less pronounced in the upper $\sim 50 \mathrm{~m}$ than below. The cross-slope distribution of temperature confirms this expectation (Fig. 15). Consistent with the vertical shift in the cross-slope thermal gradient, the jet core migrates from the surface to below $50 \mathrm{~m}$ during the simulation (Fig. 16).

\section{b. Smallness of shelf-basin exchange}

The smallness of shelf-basin exchange as measured by the fractions of particles crossing the jet $\left(\phi_{\mathrm{A}}\right.$ and $\phi_{\mathrm{C}}$; Table 2) is consistent with three factors: (i) the smallness of the cross-slope velocities (Fig. 17), (ii) the diffluent character of the cross-slope flow near the shelf edge
(Fig. 17), and (iii) the short scales of temporal correlation of the cross-slope flow at the shelf edge (Fig. 6b). If sustained, cross-slope velocities of $O(1) \mathrm{mm} \mathrm{s}^{-1}$ (Fig. 17) would correspond to a dispersion distance over a 60-day period of about $5 \mathrm{~km}$, which is much smaller than the width $6 s_{x}=6(7.4)=44 \mathrm{~km}$ of the initial jet core. The fact that the cross-slope velocities are diffluent within the core (Fig. 17) further suggests that material transport would generally not take place. Moreover, the temporal autocorrelation of the crossflow at the shelf break indicates that positive (negative) anomalies in the cross-slope flow are followed by negative (positive) anomalies after 4-5 days on average (Fig. 6b). Thus, offshore particle transport could be compensated, at least partly, by inshore particle transport on time scales which are much shorter than the 60 -day period of the Lagrangian calculation.

Notice that the three factors all relate to the temporal and/or along-slope averages of the flow and are thus of limited relevance for interpreting the transport of particles, which are subjected to instantaneous, not mean, velocities. The fact that the time-mean crossslope flow is diffluent near the shelf break (Fig. 17) illustrates that the time-mean flow cannot explain the cross-slope spreading of particles. The shelf-basin exchange in our simulation should be associated with the 

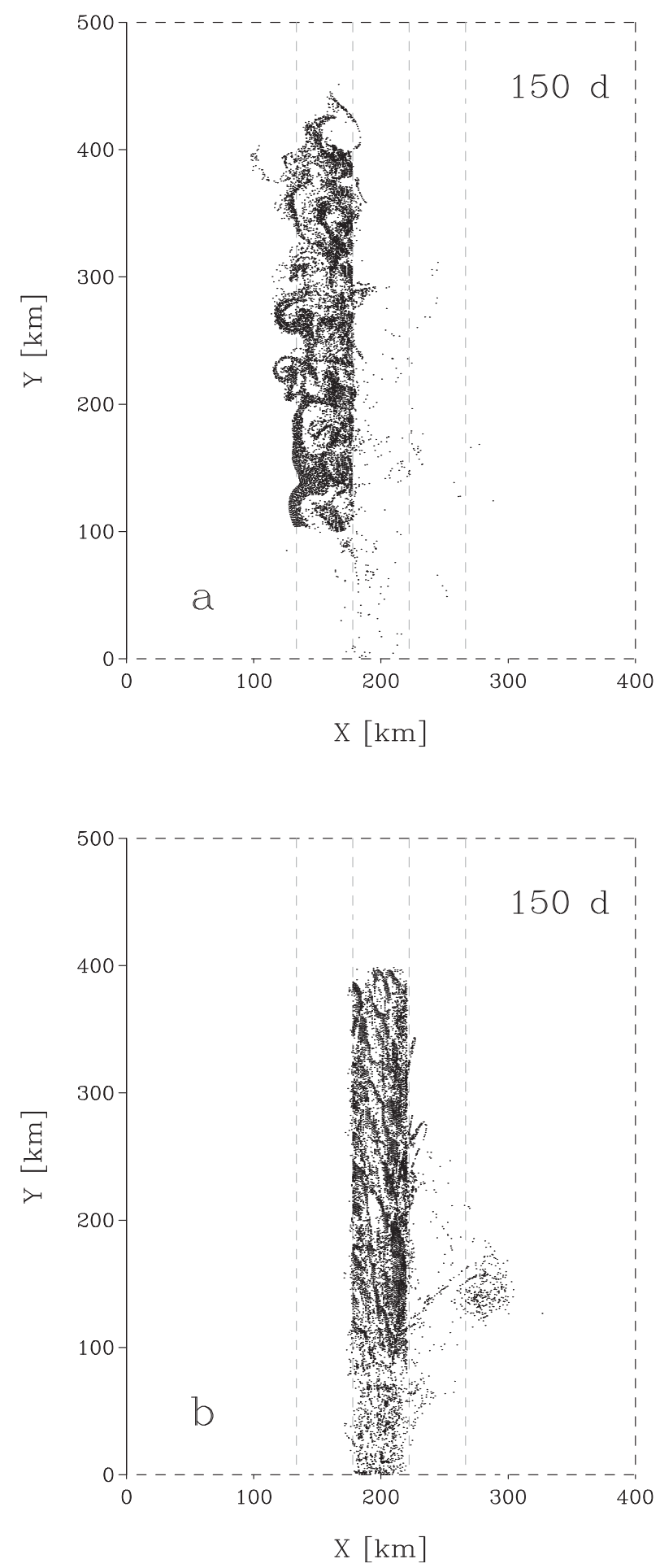

FIG. 13. Distribution of particles originating from the three bottom-most layers (a) inshore of the initial jet (region A) and (b) within the initial jet (region B). In each panel, the dashed gray lines delineate the regions inshore, within, and offshore of the initial jet. Only the particles that do not exit the domain are shown. time-dependent elements of the flow, such as frontal meanders and eddies protruding or detached from the frontal region.

\section{c. Asymmetry of cross-slope spreading}

The asymmetry of cross-slope spreading is here defined as the difference in the values of $D_{x}$ for shelf particles (originating from region $\mathrm{A}$ ) and basin particles (originating from region C). A key result of our Lagrangian calculation is the greater dispersion, in the cross-slope direction, of basin particles relatively to shelf particles (Fig. 10). To identify the cause of asymmetry, consider, in a cross-slope section, the final position of the particles originating from the surface layer (Fig. 18). Particles originating from the shelf experience modest vertical displacements (Fig. 18a). In particular, the few particles that move offshore do so very near the surface. In contrast, parcels originating from the deep basin show greater vertical motion (Fig. 18b). The parcels moving toward the shelf are subducted near the jet axis at $x=200 \mathrm{~km}$ and the parcels moving seaward are carried within the eddy dipole centered near $x=350 \mathrm{~km}$ (Figs. 3, 12). Thus, the large cross-slope spreading of basin particles compared to that of shelf particles is due to both onshore subduction below density surfaces and offshore entrainment in the dipolar vortex. It does not appear to result from the presence of the coast, since shelf particles remain at all times separated from the coast by a distance of $\sim 100 \mathrm{~km}$, exceeding severalfold the size of shelfbreak eddies (Figs. 3, 11). Both the subduction beneath density surfaces and the separation of vortices are wellstudied features of frontal dynamics (e.g., Spall 1995; Manucharyan and Timmermans 2013).

The cross-slope dispersion of shelf and basin particles released in the surface layer evolves, respectively, as $\sim t^{1.13}$ and $\sim t^{1.22}$ (Table 2). Notice that the scaling $D_{x} \propto t^{b}$ provides only an approximate description of cross-slope spreading. Systematic deviations from this scaling are observed over the 60-day period of particle transport for each region (Fig. 10). A probable source of deviations is the formation of vortices on the offshore side of the front and their excursion into the deep basin. To test this possibility, $D_{x}$ is calculated for particles originating from the surface layer in region $C$ but excluding the contribution from particles found at $x>310 \mathrm{~km}$ at $t=150$ days, that is, in the dipolar vortex present in the deep basin at the end of the simulation (last panel of Fig. 12). As expected, the displacement variance for this subset of particles diverges from that for the full set of particles originating from region C (Fig. 19): $D_{x}$ for the subset becomes appreciably smaller than $D_{x}$ for the full set for $t \gtrsim 100$ days, that is, when the vortex protrudes from the 


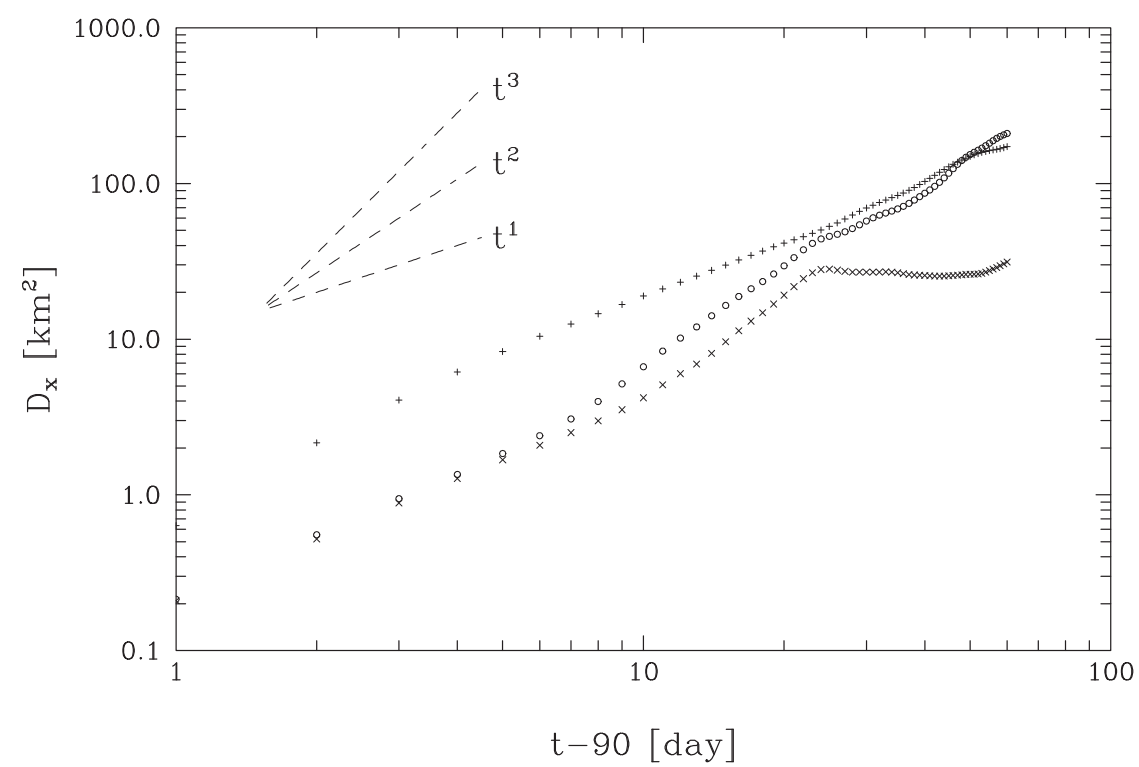

FIG. 14. Evolution of the dispersion of particles released in the three bottom-most layers inshore of the initial jet (region A; +), within the initial jet (region B; o), and within the initial jet but excluding particles found offshore of $x=250 \mathrm{~km}$ at $t=150$ days (x). The three dashed lines show the variations of $D_{x}$ with time in the diffusive regime $\left(D_{x} \propto t^{1}\right)$, the ballistic regime $\left(D_{x} \propto t^{2}\right)$, and a regime indicating either an energy cascade or shear dispersion $\left(D_{x} \propto t^{3}\right)$.

jet and moves offshore (Fig. 12). In fact, $D_{x}$ for the subset varies with time according to $D_{x} \sim t^{1.00}$ (not shown), revealing that cross-slope spreading is diffusive to a very good approximation when the offshore export in the eddy dipole is disregarded. These results highlight the role of eddies separating from the jet in both the magnitude and the character of particle transport across isobaths.

\section{d. Separation of the bottom boundary layer}

The simulated flow near the bottom along the slope is directed offshore (see inset of Fig. 17), that is, in the opposite direction to the onshore flow above. This flow is reminiscent of the bottom Ekman flow on the shelf and the upper slope, which has been investigated in a large number of model studies (Brink 2016b, and references therein). In our numerical solution, the flow near the bottom leads to the downslope transport of buoyant (relatively warm) water and favors vertical mixing near the bottom, given the Richardson-numberdependent closure scheme of the model (Mellor and Yamada 1982). As a result, the isotherms tilt downward near the bottom along the slope (Fig. 15). Thus, both the reduced cross-slope temperature gradients in the upper $\sim 50 \mathrm{~m}$ due to diffluence and the enhanced cross-slope temperature gradients below due to downslope buoyancy transport would explain the downward migration of the jet core over the course of the simulation (Fig. 16).

Having established the presence of downslope transport in a BBL, we explore the extent to which $\mathrm{BBL}$ detachment at the shelf break contributes to the seaward export of near-bottom particles (Fig. 13). To this end, consider, in the cross-slope section, the final position of particles emanating from near the bottom along the

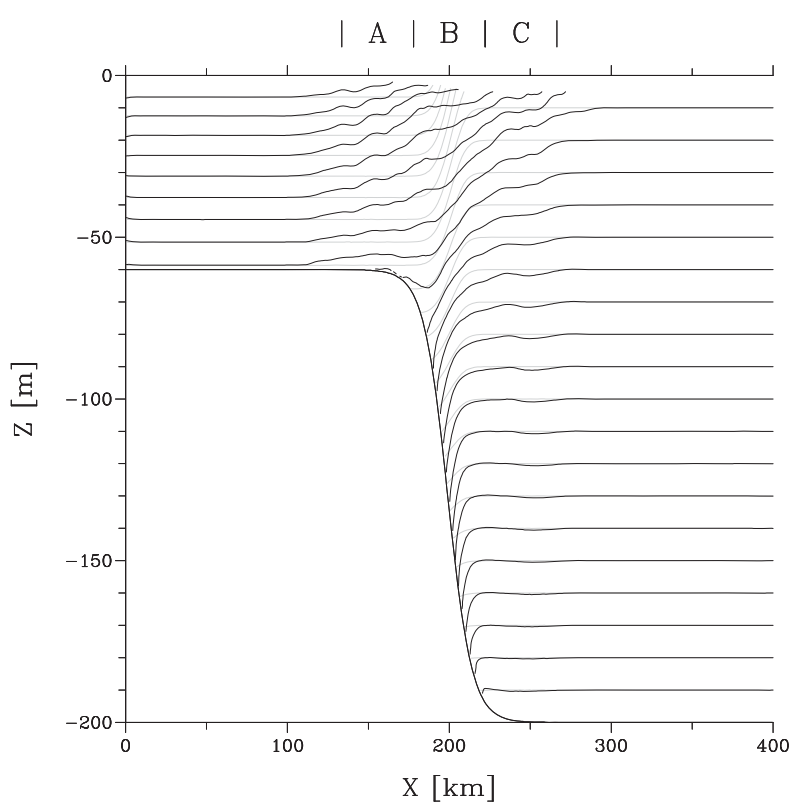

FIG. 15. Cross-slope distribution of temperature at the initial time ( $t=0$ days; gray lines) and final time ( $t=150$ days; black lines) of the simulation. The displayed values are averages from $y=100$ to $400 \mathrm{~km}$. The contour interval is $0.5^{\circ} \mathrm{C}$ (unlabeled isotherms). 


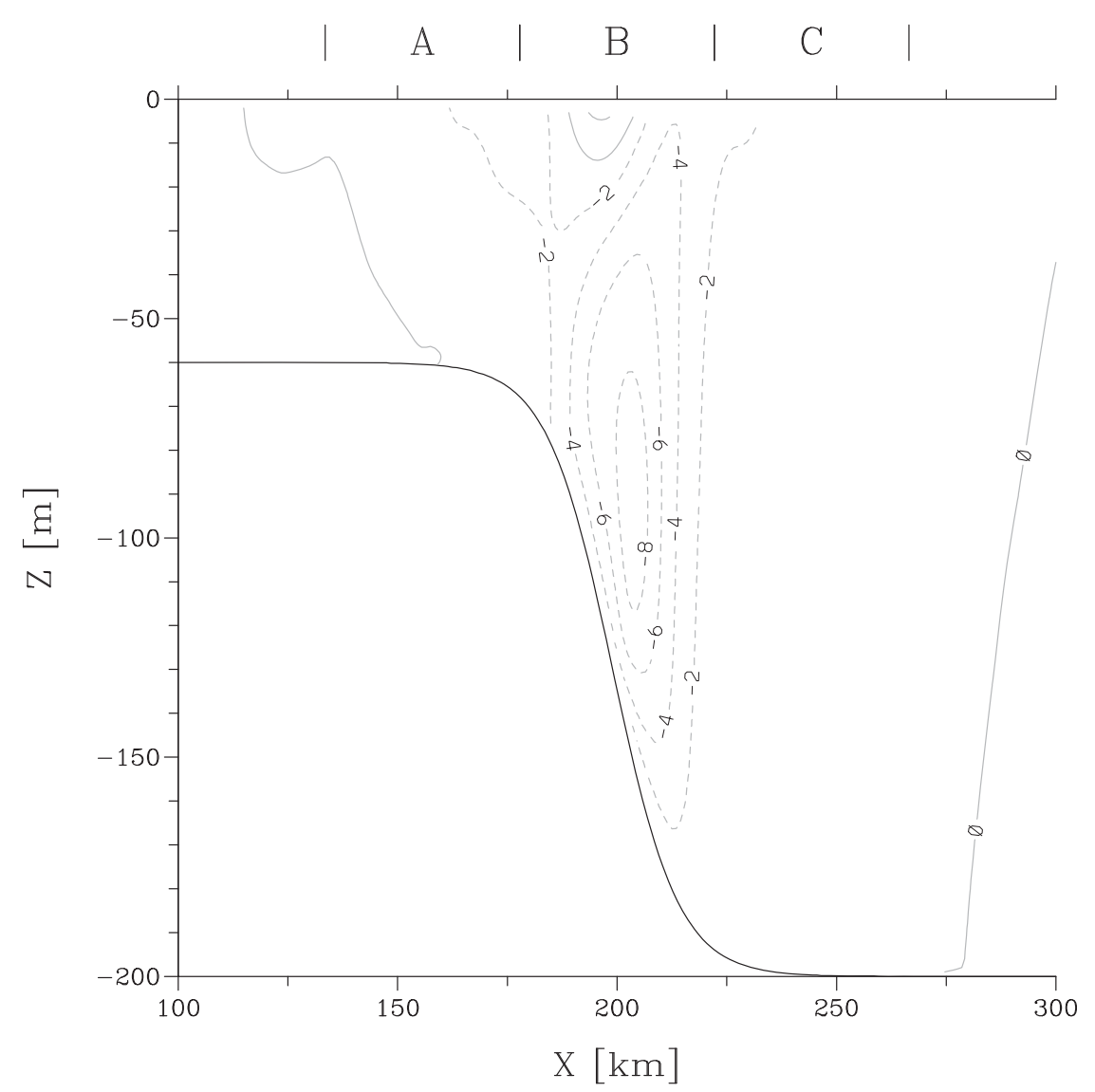

FIG. 16. Cross-slope distribution of along-slope velocity $v$. The displayed values are averages from $y=100$ to $400 \mathrm{~km}$ and from $t=90$ to 150 days. Negative (positive) values are shown with dashed (solid) lines (contour interval $=2 \mathrm{~cm} \mathrm{~s}^{-1}$ ).

shelf (region A) and the slope (region B) (Fig. 20). Shelf particles experience vertical displacements of a few tens of meters and seaward displacements of $O(100) \mathrm{km}$ over a period of 60 days along a mean path which is roughly parallel to the isotherms (Fig. 20a). Slope particles also separate from the bottom and experience vertical and seaward displacements of the same magnitude (Fig. 20b). Slope particles found between $x=250$ and $300 \mathrm{~km}$ are carried by a vortex which has separated from the shelf edge (Fig. 13b). Overall, these results suggest that the seaward export of near-bottom particles present on the shelf, the shelf edge, and the slope (Fig. 13) results from BBL detachment followed by offshore excursion of eddies.

The increase of relative dispersion with time for the bottom particles emanating from the slope (region $\mathrm{B}$ ) is estimated to $\hat{b}=1.80$, noticeably larger than for bottom particles emanating from the shelf $(\hat{b}=1.29)$ as well as for surface and middepth particles ( $\hat{b} \leq 1.41$; Table 2$)$. A fraction of bottom particles originating from the slope are entrained offshore within the eddy centered near $x=280 \mathrm{~km}, y=150 \mathrm{~km}$ at $t=150$ days (see Fig. 13b). To quantify the contribution of the eddy to cross-slope spreading, we calculate the dispersion values $D_{x}$ for bottom particles from region $B$ that are found outside of this eddy at $t=150$ days, and we compare these values to those for the entire set of bottom particles emanating from region B. Differences between the two sets of $D_{x}$ values should provide a measure of the contribution of the eddy to the cross-slope spreading of bottom particles from the slope region. We find that the dispersion $D_{x}$ of the entire set of particles, which includes particles entrained by the eddy, always exceeds the dispersion of the subset of particles which are not entrained by the eddy, the difference reaching one order of magnitude after 2 months of transport in the eddy field (cf. circles with crosses in Fig. 14). The dispersion of particles not entrained by the eddy changes very little, and even decreases slightly, after $t=110$ days (20 days for the abscissa in Fig. 14), implying that a single value of $b$ would poorly describe the evolution of these particles. Overall, these results suggest that, as for the cross-slope spreading of material near the surface 


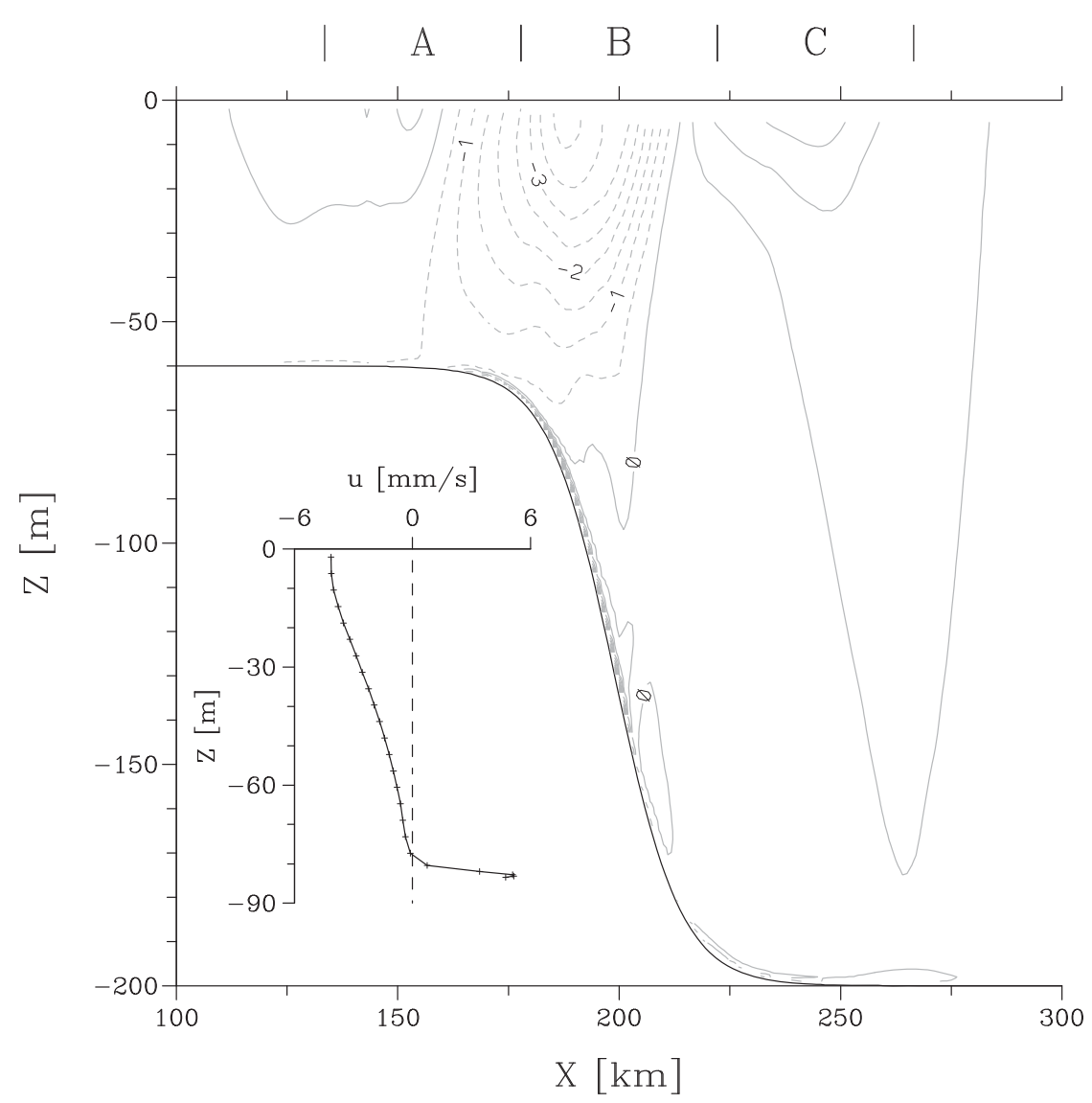

FIG. 17. Cross-slope distribution of cross-slope velocity $u$. The displayed values are averages from $y=100$ to $400 \mathrm{~km}$ and from $t=90$ to 150 days. Negative (positive) values are shown with dashed (solid) lines (contour interval $=0.5 \mathrm{~mm} \mathrm{~s}^{-1}$ ). The inset shows the vertical profile of averaged $u$ at a location along the slope $(x=188 \mathrm{~km})$.

(section $4 \mathrm{c}$ ), the cross-slope spreading of material originating from the bottom can also be significantly influenced by eddy separation.

A detachment of the BBL near the shelf break has been documented from field observations (e.g., Pickart 2000; Linder et al. 2004) and simulated with numerical models (e.g., Gawarkiewicz and Chapman 1992; Chapman and Lentz 1994). Gawarkiewicz and Chapman (1992) studied the alongshore flow on the shelf, with the coast on its right, which is produced from an inflow prescribed at the upstream boundary along the shelf. In their model, the alongshore flow gradually moves offshore due to transport in a BBL which carries buoyant water downslope. The presence of light water beneath heavier water leads to convective overturning and a vertically well-mixed density field on the shelf. The density front on the shelf moves gradually offshore under the influence of bottom friction until it reaches the shelf break. There, the adverse pressure gradient along the bottom is large enough to lead to the detachment of the BBL, which then flows offshore along upward sloping isopycnals (Gawarkiewicz and Chapman 1992). Chapman and Lentz (1994) showed that a surface-to-bottom density front can stop moving offshore and become "trapped" to an isobath even over a shelf with uniform bottom slope. The vertical velocity shear associated with the front leads to a reversal of the alongshore velocity when the water depth at the front is large enough. At this location, the cross-shelf velocity in the BBL is also reversed, causing convergence in the layer and the detachment of the layer from the bottom (Chapman and Lentz 1994).

In this study, BBL detachment occurs in the eddy field produced from the instability of the shelfbreak front. In particular, near-bottom particles from the outer shelf and the upper slope can be exported offshore in vortices produced from the frontal instability and moving seaward. This result indicates that, in addition to the adverse pressure gradient along a nonuniform slope (Gawarkiewicz and Chapman 1992) and the trapping of a surface-tobottom density front to an isobath over a uniform slope (Chapman and Lentz 1994), the separation of eddies from 

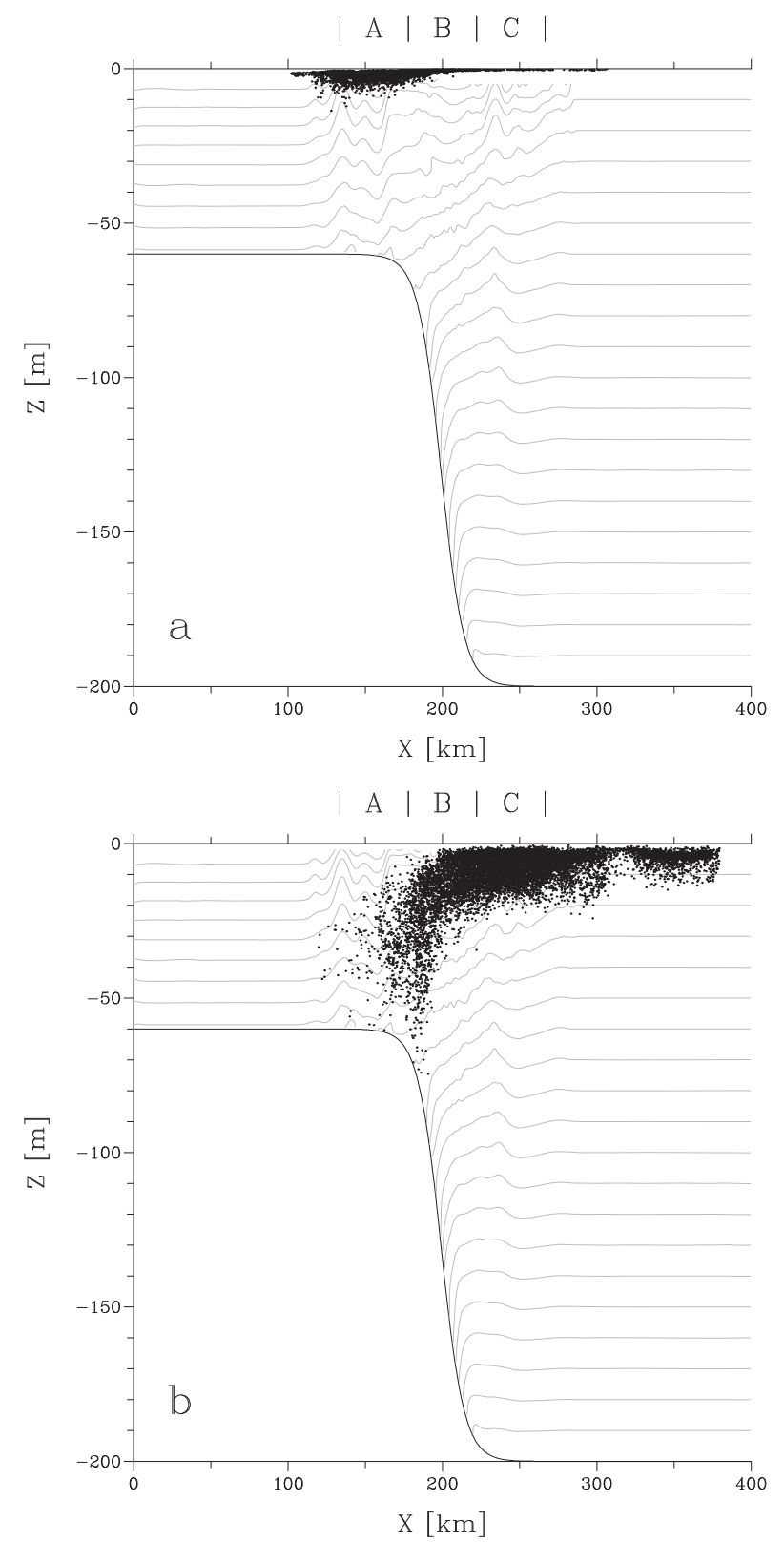

FIG. 18. Cross-slope distribution of particles released in the surface layer in (a) region $\mathrm{A}$ and (b) region $\mathrm{C}$, at the final time $t=150$ days. In both panels, the gray lines show isotherms (unlabeled) at $y=L_{y} / 2$ and $t=150$ days.

an unstable decaying front provides another mechanism for the detachment of a BBL near the shelf break.

\section{Conclusions}

In this paper, a regional primitive equation model is applied to study the material exchange which is induced by the eddy field produced from an unstable retrograde jet along the shelf break. The along-slope scale and temporal scale of correlation for the depth-averaged cross-slope velocity are found to be $O(10) \mathrm{km}$ and a few days, respectively. Whereas material detrainment from the initial path of the jet is important, material transport between the shelf and the deep ocean is found to be very small on the monthly (and shorter) time scales. The crossfrontal exchange of material is associated, not with the time-mean component of the cross-slope flow, which is small and diffluent, but with the time-dependent elements of the flow such as frontal meanders and detached eddies.

The relative dispersion of particles in the cross-slope direction is found to increase with time as $D_{x} \sim t^{b}$, where $1<b<2$. This mixed diffusive-ballistic regime seems to reflect the combined effects of (i) velocity correlation on scales which are short compared to the distance between particles of the same pair and (ii) offshore translation of particles in coherent vortices. Cross-slope spreading is found to be larger for basin particles than for shelf particles, as basin particles are both subducted onshore and entrained offshore in eddies. Particles originating from the bottom of the outer shelf and upper slope separate from the bottom and experience vertical displacements of a few tens of meters and seaward displacements of $O(100) \mathrm{km}$ during a 60 -day period. This result suggests that the eddy field produced from an unstable along-slope jet provides another mechanism for the detachment and seaward export of the bottom boundary layer near the shelf edge.

It is probably worth being explicit about the limitations of this study. One obvious caveat is that the Lagrangian motion being described is only as reliable as the velocity fields from which it has been derived. Errors arising from missing physics, subgrid-scale phenomena, boundary conditions, and the method of solution can be significant. The Smagorinsky coefficient for horizontal eddy viscosity is set to $C=0.5$ in our study (Table 1 ), greater than the range of values from 0.1 to 0.2 , which are supposed to already "work well" (Mellor 2002). Solutions obtained with $C=0.1$ and 0.2 display larger small-scale variability in surface temperature than the solution with $C=0.5$ (not shown). This larger variability may reflect the physics of the flow at small scales but also possibly the increasing influence of numerical noise as $C$ is reduced. In spite of the larger variability, compared to the results obtained with $C=0.5$ (Table 2), the fractions of parcels transported from the different regions $\left(\phi_{\mathrm{A}}, \phi_{\mathrm{B}}, \phi_{\mathrm{C}}\right)$ differ by $\leq 8 \%$ (absolute difference) and the increase of relative dispersion with time $\hat{b}$ differs by $\leq 22 \%$ (relative difference) for each region if $C=$ 0.1 or 0.2 (not shown). Nonetheless, future model studies should consider higher horizontal resolution (grid spacing $<1 \mathrm{~km}$ ) to better resolve submesoscale phenomena at the shelf break. Finally, this work is a 


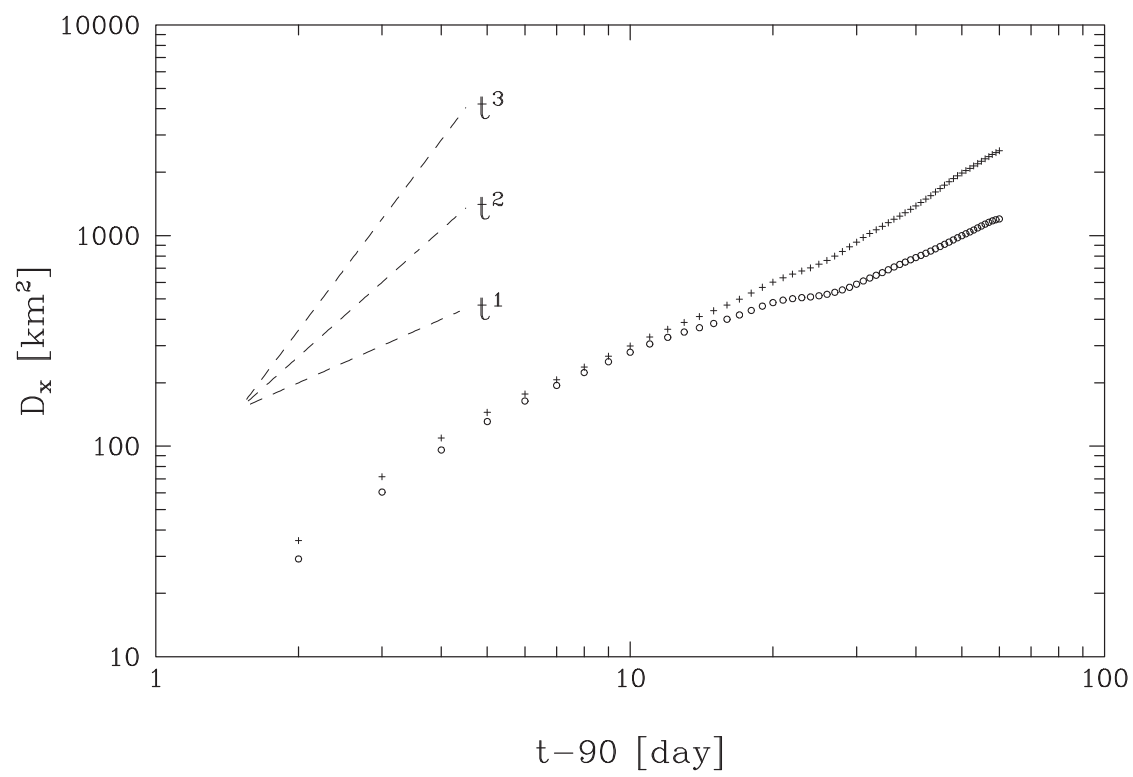

FIG. 19. Evolution of the dispersion of particles released in the surface layer offshore of the initial jet (region C). The pluses show $D_{x}$ for all particles, and the circles show $D_{x}$ for all particles except those found offshore of $x=310 \mathrm{~km}$ at $t=150$ days. The three dashed lines show the variations of $D_{x}$ with time in the diffusive regime $\left(D_{x} \propto t^{1}\right)$, the ballistic regime $\left(D_{x} \propto t^{2}\right)$, and a regime indicating either an energy cascade or shear dispersion $\left(D_{x} \propto t^{3}\right)$.

description of particle dispersion rather than the provision of new insight into frontal dynamics at the shelf edge. A theoretical understanding of the Lagrangian motion associated with shelfbreak eddies remains to be developed.

Acknowledgments. The author expresses his gratitude to the researchers who contributed to the development and public dissemination of POM [for a list of contributors, see Mellor (2002) and comments in the source code]. Discussions with Kenneth Brink, Hyodae Seo, and Weifeng Zhang have been helpful. Comments provided by Kenneth Brink on a draft are gratefully acknowledged. The criticism from two anonymous reviewers allowed us to better focus the manuscript and to significantly improve its clarity. This work has been supported by Grant OCE-1556400 from the U.S. National Science Foundation.

\section{APPENDIX}

\section{Calculation of Particle Transport}

The calculation of particle transport proceeds as follows. The model grid is a staggered $\mathrm{C}$ grid, with $(T, \rho)$ defined at the center of the grid cells and $(u, v, w)$ defined at grid points on the faces of the grid cells between the $(T, \rho)$-carrier points [the turbulence quantities $\left(q^{2}, q^{2} l\right)$ are defined at the $w$-carrier points]. In all reported calculations, particles are initially placed at $T$-carrier points. The grid cell where the particle is located is first determined from the coordinates of the particle position. If the particle is found outside of the model domain, then the calculation is interrupted for this particle, that is, the particle is "frozen" at this location. If the particle is within the domain, then the following operations are completed. The velocity components at the particle position are calculated by linearly interpolating the velocity components defined at the faces of the grid cell where the particle is located. For example, if the particle is located in the grid cell $(i, j, k)$, where $(i, j, k)$ are indices for coordinates $(x, y, \sigma)$, then the velocity component $u$ at the particle position $u_{p}$ is given by $u_{p}=\left[\left(x_{i+1}-x_{p}\right) u_{i, j, k}+\left(x_{p}-x_{i}\right) u_{i+1, j, k}\right] / \Delta x$, where $x_{i}\left(x_{i+1}\right)$ is the $x$ coordinate of the grid point carrying $u_{i, j, k}\left(u_{i+1, j, k}\right), x_{p}$ is the $x$ coordinate of the particle, and $\Delta x=x_{i+1}-x_{i}$. The new $x$ coordinate of the particle is then obtained by integrating $d x_{p} / d t=u_{p}$, that is,

$$
x_{p}(t+\Delta t)=x_{p}(t) e^{-\Delta t / t_{*}}+u_{*} t_{*}\left(1-e^{-\Delta t / t_{*}}\right),
$$

where $t_{*}=\Delta x /\left(u_{i, j, k}-u_{i+1, j, k}\right), u_{*}=\left(x_{i+1} u_{i, j, k}-x_{i} u_{i+1, j, k}\right) /$ $\Delta x$, and $\Delta t$ is the time step $\left(\Delta t=\Delta t_{I}\right.$; Table 1$)$. Note that for coding purposes, the inverse $t_{*}^{-1}$ is calculated and used to prevent a potential singularity. A similar procedure is applied for particle motion along $y$ and $\sigma$. 

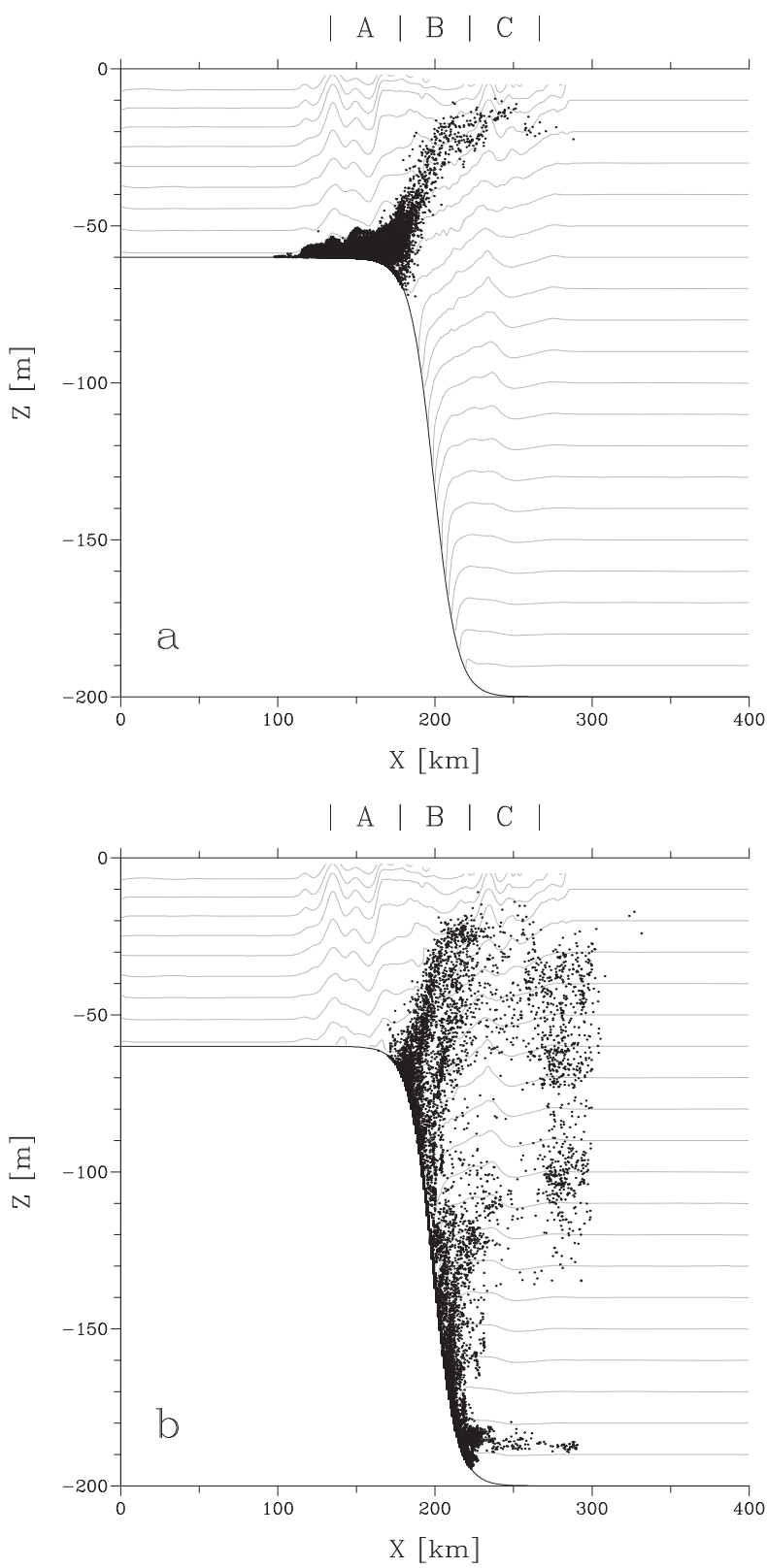

FIG. 20. Cross-slope distribution of particles released near the bottom in (a) region $\mathrm{A}$ and (b) region $\mathrm{B}$, at the final time $t=150$ days. In both panels, the gray lines show isotherms (unlabeled) at $y=L_{y} / 2$ and $t=150$ days.

It is easy to show from a Taylor series expansion that (A1) reduces to the Euler method in the limit $\Delta t / t_{*} \ll 1$. In fact, the results listed in Table 2 are very similar if the Euler method is used to integrate the particle transport (20): the fractions of parcels transported from the different regions $\left(\phi_{\mathrm{A}}, \phi_{\mathrm{B}}, \phi_{\mathrm{C}}\right)$ are identical and the increase of relative dispersion with time $\hat{b}$ differs by $\leq 1 \%$ (relative difference) for each region. Similarly, the results in Table 2 change very little if the velocity components at the particle locations are obtained from bilinear interpolation along $\sigma$ surfaces followed by linear vertical interpolation, using again the Euler method to integrate (20): the fractions of parcels transported from the different regions $\left(\phi_{\mathrm{A}}, \phi_{\mathrm{B}}, \phi_{\mathrm{C}}\right)$ change by $\leq 1 \%$ (absolute difference) and the increase of relative dispersion with time $\hat{b}$ changes by $\leq 3 \%$ (relative difference) for each region (when using bilinear interpolation, parcels are frozen when within 1 grid spacing of the lateral boundaries for coding simplicity).

\section{REFERENCES}

Barth, J., D. Bogucki, S. Pierce, and M. Kosro, 1998: Secondary circulation associated with a shelfbreak front. Geophys. Res. Lett., 25, 2761-2764, https://doi.org/10.1029/98GL02104.

Benthuysen, J., L. Thomas, and S. Lentz, 2015: Rapid generation of upwelling at a shelf break caused by buoyancy shutdown. J. Phys. Oceanogr., 45, 294-312, https://doi.org/10.1175/ JPO-D-14-0104.1.

Blumberg, A., and G. Mellor, 1987: A description of a threedimensional coastal ocean circulation model. Three-Dimensional Coastal Ocean Models, Geophys. Monogr., Vol. 4, Amer. Geophys. Union, 1-16.

Brink, K., 2016a: Continental shelf baroclinic instability. Part I: Relaxation from upwelling or downwelling. J. Phys. Oceanogr., 46, 551-568, https://doi.org/10.1175/JPO-D-15-0047.1.

— 2016b: Cross-shelf exchange. Annu. Rev. Mar. Sci., 8, 59-78, https://doi.org/10.1146/annurev-marine-010814-015717.

_ and H. Seo, 2016: Continental shelf baroclinic instability. Part II: Oscillating wind forcing. J. Phys. Oceanogr., 46, 569-582, https://doi.org/10.1175/JPO-D-15-0048.1.

Chapman, D. C., and S. J. Lentz, 1994: Trapping of a coastal density front by the bottom boundary layer. J. Phys. Oceanogr., 24, 1464-1479, https://doi.org/10.1175/1520-0485(1994)024<1464: TOACDF $>2.0 . C O ; 2$.

_ J. Barth, R. Beardsley, and R. Fairbanks, 1986: On the continuity of mean flow between the Scotian Shelf and the Middle Atlantic Bight. J. Phys. Oceanogr., 16, 758-772, https://doi.org/ 10.1175/1520-0485(1986)016<0758:OTCOMF $>2.0 . C O ; 2$.

Chen, K., and R. He, 2010: Numerical investigation of the Middle Atlantic Bight shelfbreak jet frontal circulation using a highresolution ocean hindcast model. J. Phys. Oceanogr., 40, 949964, https://doi.org/10.1175/2009JPO4262.1.

Churchill, J., and G. Gawarkiewicz, 2009: Shelfbreak frontal eddies over the continental slope north of Cape Hatteras. J. Geophys. Res., 114, C02017, https://doi.org/10.1029/2007JC004642.

Flagg, C., and R. Beardsley, 1978: On the variability of the shelf water/slope water front south of New England. J. Geophys. Res., 83, 4623-4631, https://doi.org/10.1029/JC083iC09p04623.

—, M. Dunn, D.-P. Wang, T. Rossby, and R. Benway, 2006: A study of the currents of the outer shelf and upper slope from a decade of shipboard ADCP observations in the Middle Atlantic Bight. J. Geophys. Res., 111, C06003, https://doi.org/ 10.1029/2005JC003116.

Flather, R., 1976: A tidal model of the northwest European continental shelf. Mem. Soc. Roy. Sci. Liege, 10 (6), 141-164.

Fratantoni, P. S., and R. S. Pickart, 2003: Variability of the shelf break jet in the Middle Atlantic Bight: Internally or externally forced? J. Geophys. Res., 108, 3166, https://doi.org/10.1029/ 2002JC001326. 
,-- D. Torres, and A. Scotti, 2001: Mean structure and dynamics of the shelfbreak jet in the Middle Atlantic Bight during fall and winter. J. Phys. Oceanogr., 31, 2135-2156, https://doi.org/10.1175/1520-0485(2001)031<2135: MSADOT $>2.0 . \mathrm{CO} ; 2$.

Garvine, R., K.-C. Wong, G. Gawarkiewicz, R. McCarthy, R. Houghton, and F. Aikman, 1988: The morphology of shelfbreak eddies. J. Geophys. Res., 93, 15 593-15 607, https:// doi.org/10.1029/JC093iC12p15593.

Gawarkiewicz, G., 1991: Linear stability models of shelfbreak fronts. J. Phys. Oceanogr., 21, 471-488, https://doi.org/10.1175/ 1520-0485(1991)021<0471:LSMOSF > 2.0.CO;2.

_ and D. Chapman, 1992: The role of stratification in the formation and maintenance of shelf-break fronts. J. Phys. Oceanogr., 22, 753-772, https://doi.org/10.1175/1520-0485(1992)022<0753: TROSIT $>2.0 . \mathrm{CO} ; 2$.

, K. Brink, F. Bahr, R. Beardsley, M. Caruso, J. Lynch, and C.-S. Chiu, 2004: A large amplitude meander of the shelfbreak front during summer south of New England: Observations from the shelfbreak PRIMER experiment. J. Geophys. Res., 109, C03006, https://doi.org/10.1029/2002JC001468.

Hoskins, B. J., 1982: The mathematical theory of frontogenesis. Annu. Rev. Fluid Mech., 14, 131-151, https://doi.org/10.1146/ annurev.fl.14.010182.001023.

Houghton, R., 1997: Lagrangian flow at the foot of a shelfbreak front using a dye tracer injected into the bottom boundary layer. Geophys. Res. Lett., 24, 2035-2038, https://doi.org/10.1029/97GL02000.

_ - and M. Visbeck, 1998: Upwelling and convergence in the Middle Atlantic Bight shelfbreak front. Geophys. Res. Lett., 25, 2765-2768, https://doi.org/10.1029/98GL02105.

Huthnance, J., 1995: Circulation, exchange and water masses at the ocean margin: The role of physical processes at the shelf edge. Prog. Oceanogr., 35, 353-431, https://doi.org/10.1016/ 0079-6611(95)80003-C.

Klein, P., B. L. Hua, G. Lapeyre, X. Capet, S. Le Gentil, and H. Sasaki, 2008: Upper ocean turbulence from high-resolution 3D simulations. J. Phys. Oceanogr., 38, 1748-1763, https://doi.org/10.1175/ 2007JPO3773.1.

LaCasce, J. H., 2008: Statistics from Lagrangian observations. Prog. Oceanogr., 77, 1-29, https://doi.org/10.1016/j.pocean.2008.02.002.

Lentz, S., 2010: The mean along-isobath heat and salt balances over the Middle Bight continental shelf. J. Phys. Oceanogr., 40, 934-948, https://doi.org/10.1175/2009JPO4214.1.

Linder, C., and G. Gawarkiewicz, 1998: A climatology of the shelfbreak front in the Middle Atlantic Bight. J. Geophys. Res., 103, 18 405-18 423, https://doi.org/10.1029/98JC01438.

- - - and R. Pickart, 2004: Seasonal characteristics of the bottom boundary layer detachment at the shelfbreak front in the Middle Atlantic Bight. J. Geophys. Res., 109, C03049, https://doi.org/10.1029/2003JC002032.

Lozier, S., and G. Gawarkiewicz, 2001: Cross-frontal exchange in the Middle Atlantic Bight as evidenced by surface drifters. J. Phys. Oceanogr., 31, 2498-2510, https://doi.org/10.1175/ 1520-0485(2001)031<2498:CFEITM > 2.0.CO;2.

, and M. Reed, 2005: The influence of topography on the stability of shelfbreak fronts. J. Phys. Oceanogr., 35, 1023-1036, https://doi.org/10.1175/JPO2717.1.
,-- , and G. Gawarkiewicz, 2002: Instability of a shelfbreak front. J. Phys. Oceanogr., 32, 924-944, https://doi.org/10.1175/ 1520-0485(2002)032<0924:IOASF $>2.0 . \mathrm{CO} ; 2$.

Mahadevan, A., and A. Tandon, 2006: An analysis of mechanisms of submesoscale vertical motion at ocean fronts. Ocean Modell., 14, 241-256, https://doi.org/10.1016/j.ocemod.2006.05.006.

Manucharyan, G., and M.-L. Timmermans, 2013: Generation and separation of mesoscale eddies from surface ocean fronts. J. Phys. Oceanogr., 43, 2545-2562, https://doi.org/10.1175/ JPO-D-13-094.1.

Mellor, G., 2002: Users guide for a three-dimensional, primitive equation, numerical ocean model. Program in Atmospheric and Oceanic Sciences, Princeton University, $42 \mathrm{pp}$.

— model for geophysical fluid problems. Rev. Geophys., 20, 851875, https://doi.org/10.1029/RG020i004p00851.

Pickart, R., 2000: Bottom boundary layer structure and detatchment in the shelfbreak jet of the Middle Atlantic Bight. J. Phys. Oceanogr., 30, 2668-2686, https://doi.org/10.1175/ 1520-0485(2001)031<2668:BBLSAD>2.0.CO;2.

Rypina, I., A. Kirincich, S. Lentz, and M. Sundermeyer, 2016: Investigating the eddy-diffusivity concept in the coastal ocean. J. Phys. Oceanogr., 46, 2201-2218, https://doi.org/10.1175/ JPO-D-16-0020.1.

Shcherbina, A., E. D'Asaro, C. Lee, J. Klymak, J. Molemaker, and J. McWilliams, 2013: Statistics of vertical vorticity, divergence, and strain in a developed submesoscale turbulence field. Geophys. Res. Lett., 40, 4706-4711, https://doi.org/10.1002/ grl.50919.

Smagorinsky, J., 1963: General circulation experiments with the primitive equations: I. The basic experiment. Mon. Wea. Rev., 91, 99-164, https://doi.org/10.1175/1520-0493(1963)091<0099: GCEWTP $>2.3$.CO;2.

Spall, M. A., 1995: Frontogenesis, subduction, and cross-front exchange at upper-ocean fronts. J. Geophys. Res., 100, 25432557, https://doi.org/10.1029/94JC02860.

Thomas, L., A. Tandon, and A. Mahadevan, 2008: Submesoscale processes and dynamics. Ocean Modeling in an Eddying Regime, Geophys. Monogr., Vol. 177, Amer. Geophys. Union, 17-38

Todd, R., G. Gawarkiewicz, and B. Owens, 2013: Horizontal scales of variability over the Middle Atlantic Bight shelf break and continental rise from finescale observations. J. Phys. Oceanogr., 43, 222-230, https://doi.org/10.1175/JPO-D-12-099.1.

Vallis, G. K., 2006: Atmospheric and Ocean Fluid Dynamics: Fundamentals and Large-Scale Circulation. Cambridge University Press, $745 \mathrm{pp}$.

Xue, H., and J. Bane, 1997: A numerical investigation of the Gulf Stream and its meanders in response to cold air outbreaks. J. Phys. Oceanogr., 27, 2606-2629, https://doi.org/10.1175/ 1520-0485(1997)027<2606:ANIOTG > 2.0.CO;2.

Zhang, W., and G. Gawarkiewicz, 2015: Length scale of the finiteamplitude meanders of shelfbreak fronts. J. Phys. Oceanogr., 45, 2598-2620, https://doi.org/10.1175/JPO-D-14-0249.1.

,$- \frac{1}{-}$ D. McGillicuddy, and J. Wilkin, 2011: Climatological mean circulation at the New England shelf break. J. Phys. Oceanogr., 41, 1874-1893, https://doi.org/10.1175/2011JPO4604.1. 